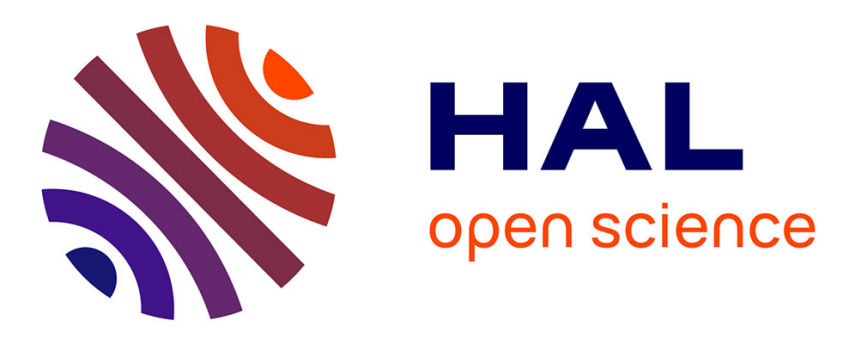

\title{
Shadows of bygone lives: The histories of spiritual words in northern Vanuatu
}

Alexandre François

\section{To cite this version:}

Alexandre François. Shadows of bygone lives: The histories of spiritual words in northern Vanuatu. Robert Mailhammer. Lexical and structural etymology: Beyond word histories, DeGruyter Mouton, pp.185-244, 2013, Studies in Language Change, 978-1614510598. 10.1515/9781614510581.185. halshs-00869690

\section{HAL Id: halshs-00869690 \\ https://shs.hal.science/halshs-00869690}

Submitted on 18 Oct 2013

HAL is a multi-disciplinary open access archive for the deposit and dissemination of scientific research documents, whether they are published or not. The documents may come from teaching and research institutions in France or abroad, or from public or private research centers.
L'archive ouverte pluridisciplinaire HAL, est destinée au dépôt et à la diffusion de documents scientifiques de niveau recherche, publiés ou non, émanant des établissements d'enseignement et de recherche français ou étrangers, des laboratoires publics ou privés. 


\section{Lexical and \\ Structural \\ Etymology}

Edited by

Robert Mailhammer

DE GRUYTER

MOUTON 


\section{Table of contents}

Contact details and affiliations of contributors - $v$

Abbreviations - vii

Robert Mailhammer

Introduction: Etymology beyond word histories - 1

Robert Mailhammer

Towards a framework of contact etymology -9

Harold Koch and Luise Hercus

Obscure vs. transparent cognates in linguistic reconstruction - 33

Harold Koch

The etymology of a paradigm: the Pama-Nyungan 3SgF reconsidered -53

Rachel Hendery

Constructional etymology: The sources of relative clauses - 83

Theo Vennemann

Concerning myself -121

Patrick McConvell

Granny got cross: semantic change of kami 'mother's mother' to 'father's mother' in Pama-Nyungan - 147

Alexandre François

Shadows of bygone lives: The histories of spiritual words in northern Vanuatu -185

Meredith Osmond

Markers of the spirit world in Oceanic languages - 245

John Giacon

Etymology of Yuwaalaraay Gamilaraay bird names - 251

David Nash

The smuggled budgie: case study of an Australian loanblend - 293

Luise Hercus

Archaisms in placenames in Arabana-Wangkangurru country - 313

Subject index -323 


\section{Shadows of bygone lives: The histories of spiritual words in northern Vanuatu}

\section{Studying etymology with unwritten languages}

Many linguists are familiar with etymologies in Indo-European languages, and how they help us discover invisible threads between words that have become widely separated in form or in meaning. ${ }^{1}$ Etymology teaches us that miracle, marvel and mirror all stem from a single Latin verb mīāri 'wonder, admire' respectively via its derived nouns mīrāculum, Late Latin mīrābilia, and Old French mireor. The deep-reaching insights of Proto Indo-European reconstruction even allow us to find connections between the words idea, view, advice, story and witty: they all stem ultimately from a single PIE root whose form can be reconstructed as *weyd 'see, know' (cf. Chantraine 1968: 796). Similar etymological links can be drawn between quick, vital, bio and zoo $<^{\star} g^{w} y e h_{3}$ 'live' (Chantraine 1968: 176); between culture, wheel, colonial, polar, cyclone, bike and chakra $<^{\star} k^{w}$ el 'turn, make a turn' (Chantraine 1968: 878); or between diary, Zeus, deity, journey, diva and Tuesday $<{ }^{\star}$ dey- 'bright, shine' (Chantraine 1968: 399).

A fair proportion of our etymological knowledge about Indo-European languages rests on the careful philological analysis of written documents (e.g. Benveniste 1969), some of which are extremely ancient. This is so true that the existence of a long tradition of writing might be taken by some as a preliminary condition for any serious endeavour in the realm of etymology. Could the same sort of research be carried out on languages with no written tradition at all, and for which we can only access present-day forms? The answer to this question, of course, is positive. While philology is restricted to the study of written documents from the past, the study of etymology is a branch of historical linguistics, which can also take unwritten languages as its object. Simply, instead of involving a comparison between various historical attested stages of a single language, etymology will rest here on comparison across related languages.

1 I am grateful to Andrew Pawley, Malcolm Ross, Robert Blust, Sabine Hess, Margaret Jolly, Siva Kalyan and Maïa Ponsonnet, for their helpful comments on earlier versions of this article. I also thank Marie Durand who supplemented my Mwerlap data with new words and cultural comments. Finally, such a study would not have been possible without the help and kindness of the many people from northern Vanuatu who patiently taught me their languages. 
As other chapters in this volume show, etymological research based on previously unwritten languages is not only feasible, but it has long been carried out in various parts of the world. Oceanic languages, which are the focus of the present chapter, have been the object of comparative research as early as the 18th century, an effort which culminated in Dempwolff (1938) demonstrating the unity of the Oceanic subgroup. Etymological research in this domain is continued nowadays by various scholars - with a special mention for the Oceanic lexicon project which Malcolm Ross, Andrew Pawley and Meredith Osmond have led since 1998 (see references). These Oceanic studies form part of a larger domain of research on Austronesian etymologies, which for several decades has been dominated by the prolific work of Robert Blust.

Rather than undertaking a general survey of the etymological research undertaken on these vast language families, the present study will focus on a set of 17 closely related Oceanic languages spoken in northern Vanuatu. I will narrow the domain of investigation to the "spiritual" field: words for mind, soul, spirit, ghost, shaman, supernatural powers and other related concepts. This survey will lead me to highlight the essential role played by ancestral spirits in the cultural landscape and social representations of northern Vanuatu communities. Spirits are present in the land, in rocks and magic stones, in the depths of caves and volcanoes. They live on in the secret societies where their presence is symbolically reenacted. Ancestral spirits are the source of various dances and musical instruments, of the language of poetry, of many myths and stories; their magic power can be harnessed by dancers, poets, shamans, sorcerers. All these connections across different social domains have left traces in the modern languages - yet these traces are sometimes hidden, and can only be detected by the tools of the historical linguist.

In a way, the present study can be read as an introduction to the spiritual world of island Melanesia, from the particular angle of etymology, or "linguistic archaeology". It should be of interest to linguists, but also to anthropologists and other scholars in social sciences, with no specific background in linguistics. Even though the phonetic transcriptions of word forms will necessarily comply, for the sake of accuracy, with the sometimes opaque conventions of the International Phonetic Alphabet (IPA), the non-linguist reader should still be able to follow the reasonings about semantic description and reconstruction.

My aim will be to illustrate a point that historical linguists have already shown many times (see Biggs, Blust, Pawley, Ross in the references): namely, that lexical comparison among unwritten languages can provide valuable insights in the domain of ethnographic analysis and culture history. For example, I will show that the word no-tom in the language Mwerlap, which refers to 'a magical sign put up to keep ghosts away', is cognate with $n \varepsilon$-tckp ${ }^{w}$ 'graveyard' 
in the neighbouring language Mwotlap (§4.5.2); and that both words ultimately reflect a Proto Oceanic root ${ }^{\star} t a^{m} b u$ 'off limits, forbidden' - itself the source of English taboo. In proposing such hypotheses, scholars need to constantly bear in mind the risk of proposing false etymologies based on mere similarity or impressionistic likelihood. This is where the power of the comparative method becomes crucial, as it defines a solid methodology based on the observation of regular sound correspondences, as well as the identification of convincing semantic links.

This study will unfold in three major parts. After locating the target languages in their geographic and historical context (Section 2), I will outline the methodological principles that underlie the search for reliable etymologies (Section 3). Once the general points of the method are defined, section 4 will delve into the fine-grained detail of spiritual words in this part of Melanesia, as we reconstruct the semantic evolution of about 80 roots or cognate sets. This survey will hopefully show how the discipline of etymology, as long as it complies with strict linguistic principles, is able to uncover semantic networks of the past - even when centuries of phonetic or semantic change have made them difficult to detect in modern languages.

\section{The Torres-Banks languages of north Vanuatu}

\subsection{The languages of Vanuatu}

One of the archipelagoes of Island Melanesia, the modern country of Vanuatu known as the New Hebrides until its independence in 1980 - hosts the world's highest density of languages per capita (Crowley 2000). A total of 106 vernacular languages have been recorded there (Tryon 1976; Lynch and Crowley 2001) for a current population of just 234,000 inhabitants. Most of that population still lives in rural areas, where they essentially pursue traditional activities of farming and fishing. Their current way of life largely continues that of their ancestors, even though modern times have brought in various forms of cultural change - such as the Christian religion, or cash economy. Figure 1 situates Vanuatu within Island Melanesia and the Pacific.

The present study focuses on the languages of the Torres and Banks Islands, in the northernmost area of Vanuatu. Figure 2 provides a linguistic map of the area. Each language name is followed by an approximate number of speakers, and by a three-letter abbreviation which will be used throughout this paper.

Until recently, the only detailed source of documentation about these northern languages was the pioneering work of the Anglican missionary and linguist Robert 


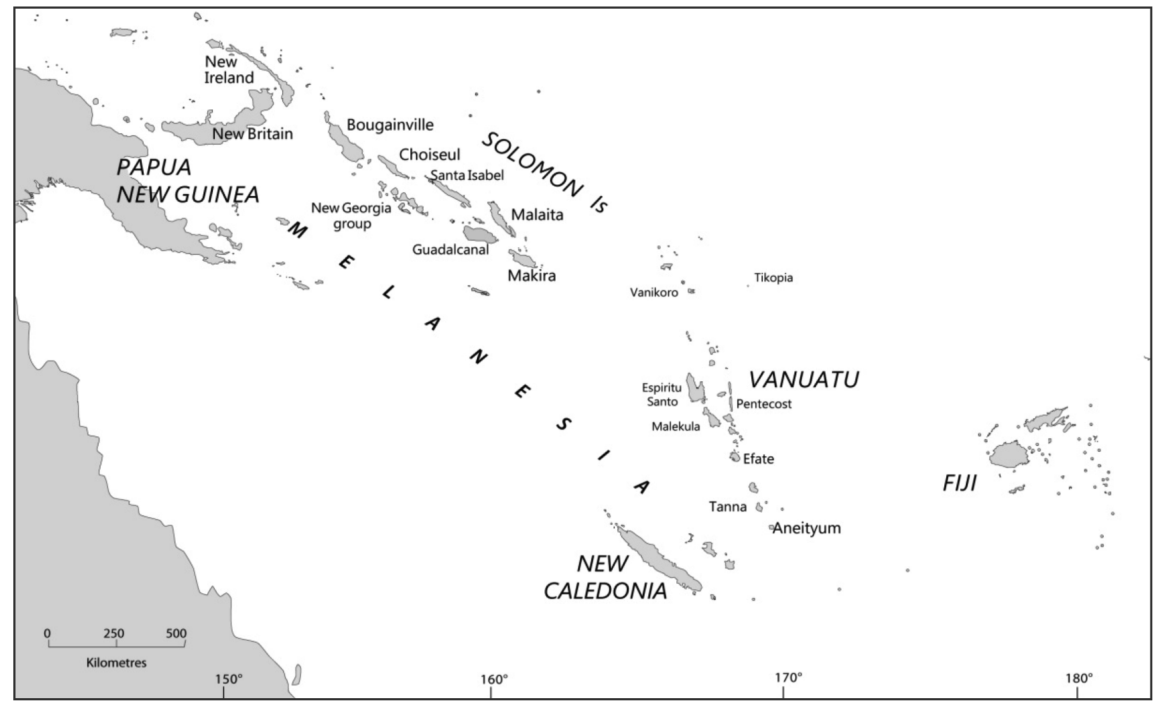

Figure 1: Situation of Vanuatu in the Pacific
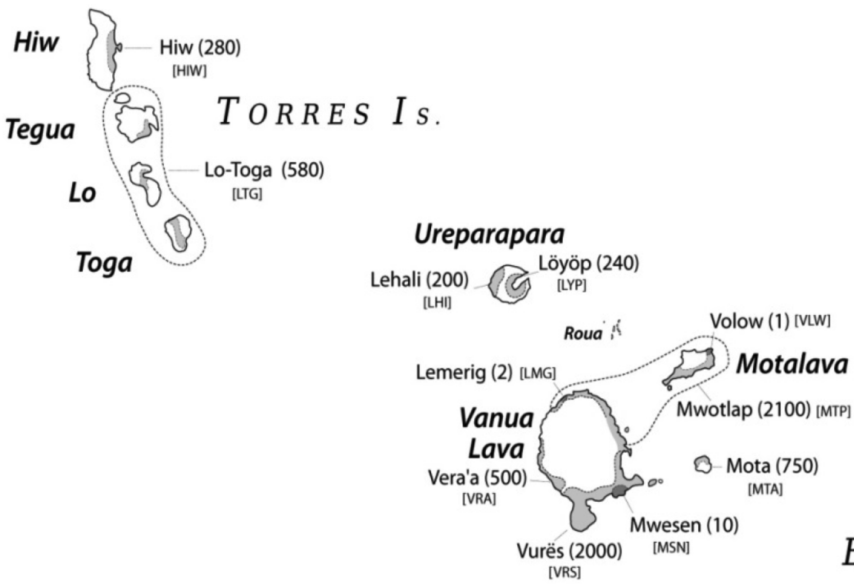

BANKSIs.

uninhabited area

monolingual area

bilingual area

(280) number of speakers

$25 \mathrm{~km}$

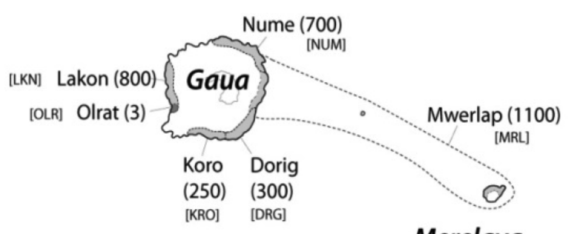

Merelava

Figure 2: The 17 languages of northern Vanuatu (Torres and Banks Is) 
Codrington, at the end of the 19th century (see references). His grammatical and ethnographic descriptions were mostly focused on the small island of Mota, yet occasionally reached out to neighbouring islands. While anthropologists have maintained a constant interest in the region (Ivens 1931; Vienne 1972, 1984; Lanouguère-Bruneau 2002; Mondragón 2004; Hess 2009), no linguistic study other than wordlists (Tryon 1976) was published about the Torres-Banks area during the whole of the 20th century. The present chapter rests on firsthand data I collected during a number of field trips in Vanuatu since $1997 .^{2}$

\subsection{Three millennia of diversification}

The linguistic density of Vanuatu does not reflect deep genetic diversity: all these languages share the same ancestor, Proto Oceanic - itself a member of the vast Austronesian family. There are strong arguments for equating Proto Oceanic with the language that was spoken by the bearers of the archaeological culture known as "Lapita" - the seafaring population who first settled the archipelagoes between the Solomons and Western Polynesia about 3000 years ago (Pawley 2003, 2007, 2008, 2010). In a way similar to the fragmentation of Latin into a multitude of Romance languages and dialects, the linguistic diversity observed today in Vanuatu results from three millennia of in situ diversification from what was once a single language spoken across a vast social network (François 2011a).

During the centuries following its initial settlement, Vanuatu formed a vast dialect continuum in which communalects remained in constant contact through trade, interisland marriage and other forms of alliances. Every time a linguistic innovation emerged somewhere in the network, it would diffuse to a more or less extended portion of the network. The isogloss it defined was sometimes limited to just a village, sometimes to several islands, and sometimes swept through even larger territories as it expanded across entire archipelagoes (François 2011a,b). Rather than yielding neat subgroups, this wave-like process of diversification naturally resulted in a map of constantly intersecting isoglosses. The modern outcome is a vast web of "linkages," i.e. linguistic areas resulting from the breakup of an earlier dialect continuum (Ross 1988: 8).

Vanuatu as a whole can be considered a linkage, which in turn includes various loosely bound linkages of different scales. This chapter will especially

2 I occasionally compared my fieldwork data with Codrington and Palmer (1896) for Mota, and with Hyslop (n.d. $a-b$ ) for Vurës and Vera'a. Marie Durand has provided some personal comments regarding Mwerlap. 
mention "North Central Vanuatu" - whose putative protolanguage PNCv is being reconstructed by Clark (2009) - as well as the "Torres-Banks linkage” (François $2011 b$ ), the focus of this study. Figure 3 situates the latter in the context of other subgroups and linkages of Oceanic. Following conventions proposed by Ross (1988), double lines indicate linkages as opposed to discrete subgroups.

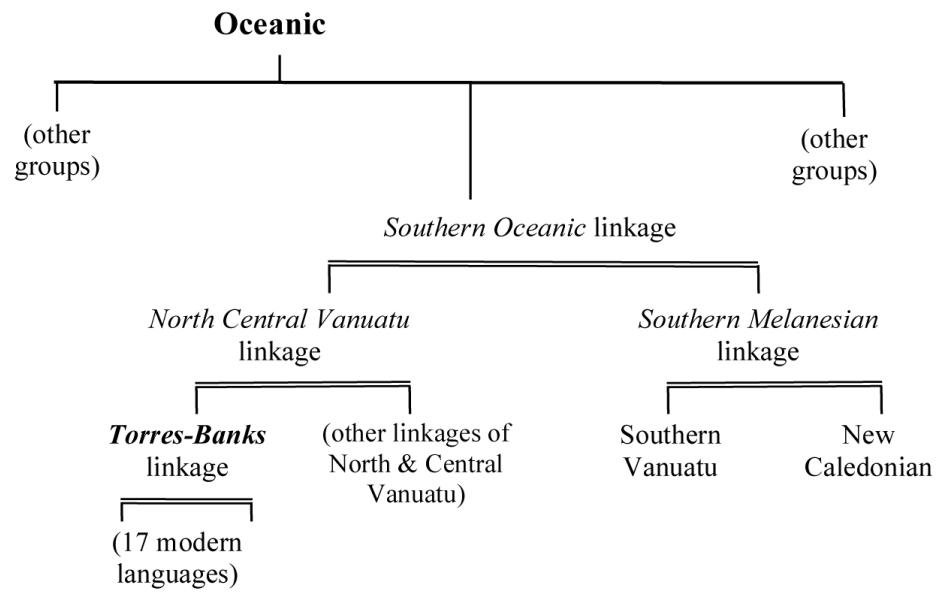

Figure 3: Proto Oceanic has split into various dialect networks, which have given rise to loosely-bound linkages of various sizes

In the remainder of this paper, lexical reconstructions will correspond to the level of "Proto Torres-Banks" - the common ancestor of the Torres-Banks linkage - yet I will occasionally also cite reconstructions at the higher levels of Proto North-Central Vanuatu (PNcv, Clark 2009) and Proto Oceanic (POc).

\subsection{Diversification and cognate identification}

Even though they remained in mutual contact during the three millennia of their settlement, the languages of northern Vanuatu have diverged so as to lose mutual intelligibility.

As an illustration of the modern diversity, (1) gives the term for 'woman' in the 17 languages of the area. Languages are ranked geographically from northwest to southeast, and designated by their abbreviation (see Figure 2): ${ }^{3}$

3 All forms are given in IPA. Nouns are given in their citation form, which occasionally includes a prefix of the form $n$ - or $n V$ - : e.g. $n a-l k^{w} v \beta ı n$. This is a noun article which many languages have incorporated into their phonological word (François 2007). Even though this article can be reconstructed (as *na), I will leave it out of my lexical reconstructions. 


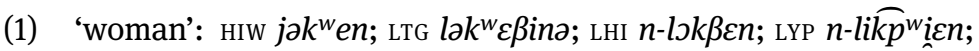
VLW $n-l \varepsilon^{\eta} \widehat{g b^{w}} \varepsilon \beta I n$; MTP na-l $\widehat{k p}^{w} \mho \beta I n$; LMG $n-r \varepsilon \eta \varepsilon$; VRA $r \varepsilon \eta \varepsilon$; VRS $r \varepsilon \widehat{k p}{ }^{w} \varepsilon$; MSN $r \varepsilon \widehat{k p}^{w} \varepsilon$; MTA taßne; NUM tawa; DRG $r \widehat{k p}^{w} a$; KRO ra $\widehat{k p} p^{w} a$; OLR $r a \widehat{k p}{ }^{w} a$;

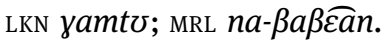

The processes whereby northern Vanuatu languages diverged from their common ancestor took mostly two forms: sound change and lexical replacement (François 2011b: 192). A form like Mwerlap na- $\beta a \beta \widehat{\varepsilon a n}$ is conservative of the Proto Oceanic etymon for 'woman', namely *pine or *pa-pine, and has simply gone through sound change. Mota taßne reflects a slightly different etymon ${ }^{\star}$ ta-pine (§4.1.2). Likewise the first six forms of (1), whose protoform reconstructs as ${ }^{\star} l o^{m} b^{w} e$-ßine, also keep a vestigial trace of POc ${ }^{\star}$ pine - even though it was occasionally made invisible by subsequent sound change, as in Hiw jakwen. By contrast with these cases of partial cognacy, the remaining nine forms of (1) illustrate various events of lexical replacement with material that bears no relation at all to the POc etymon.

The amount of phonetic erosion and lexical change that took place in the history of northern Vanuatu languages makes it necessary to define strict methodological principles with the aim to secure historical hypotheses, and minimize the risk of false etymologies.

\section{The methodology of lexical reconstruction}

The principal steps to be taken in lexical reconstruction and etymology can be outlined as follows. First, knowledge of regular sound correspondences across languages makes it possible to ascertain which words are cognate. Solid hypotheses about sound change enable the reconstruction of a protoform for each cognate set, i.e. the most likely phonological form taken by the word that was once at the source of the modern cognate set. Finally, the meanings of modern reflexes form the basis on which earlier meanings, and processes of semantic change, can be hypothesized.

The following pages will briefly illustrate the process with a few examples. This will serve as an introduction to the etymological explorations presented in Section 4.

\subsection{Establishing regular correspondences}

In spite of the occasionally extreme linguistic divergence illustrated in (1), the comparison of lexical material across northern Vanuatu does bring about regular 
correspondences. For example, consider the modern words for 'stingray' (2) and for 'hibiscus' (3):

(2) 'stingray': HIW $\beta{ }^{g}{ }^{g}$; LTG $\beta \varepsilon r$; LHI $n$ - $\beta æ j$; LYP $n-\beta r j$; vLW $n-\beta I j$; MTP $n \varepsilon-\beta \varepsilon j$; LMG $n-\beta \varepsilon r$; VRA $f \varepsilon r$; VRS $\beta œ r$; MSN $\beta \varepsilon r$; MTA $\beta a r$; NUM $f \varepsilon r$; DRG $\beta a r r$;RO $\beta \overparen{\varepsilon a r}$; OLR $\beta a j$; LKN $\beta æ:$; MRL $n \varepsilon-\beta \varepsilon r$.

(3) 'hibiscus': HIW $\beta{ }^{g}{ }_{L}$; LTG $\beta$ Jr; LHI $n-\beta v j$; LYP $n-\beta I j$; vLW $n-\beta \varepsilon j$; MTP $n \varepsilon-\beta \varepsilon j$; LMG $n-\beta \varepsilon r$; VRA $f \varepsilon r$; VRS $\beta œ r$; MSN $\beta$ Jr; MTA $\beta a r$; NUM far; DRG $\beta a r r$; кRо $\beta \overparen{\varepsilon a r}$; OLR $\beta a$; LKN $\beta a$; MRL no- $\beta \widetilde{\mathrm{JB}}$.

The correspondences regarding consonants are easy to spot. Thus a word-initial [f] in Vera'a and Nume corresponds to $[\beta]$ elsewhere. A velar lateral $\left[{ }^{g_{L}}\right]$ in Hiw corresponds to a trill [r] in some languages, a glide [j] in others, and a long vowel in Lakon (François 2011a: 150). Based on these correspondences, one can formulate hypotheses on the nature of the protophonemes (the source phonemes in the protolanguage) reflected by these modern forms. For example, it is likely that $[\beta]$ and $[\mathrm{f}]$ reflect a former consonant ${ }^{\star} \beta$. As for the second set of correspondences, it demonstrably reflects a former apical trill ${ }^{\star}$ r. Such hypotheses on individual segments are a preliminary step before entire words can be reconstructed - as we will see below.

Correspondences with respect to vowels are more complex, yet they also prove highly regular. The forms in (2) 'stingray' illustrate a first set of correspondences, outlined in (4):

(4) Vowel correspondence set I:

HIW /J/; LTG / $\varepsilon /$; LHI /æ/; LYP /I/; VLW /I/; MTP / $\varepsilon /$; LMG / $\varepsilon /$; VRA / $\varepsilon /$; VRS /œ/; MSN $/ \varepsilon /$; MTA /a/; NUM / $\varepsilon /$; DRG /a:/; KRO / $\overparen{\varepsilon a / ; ~ O L R ~ / a / ; ~ L K N ~ / æ / ; ~ M R L ~ / ~} / \varepsilon /$.

A very similar distribution of vowels can be found, for example, in the numeral 'four':

(5) 'four': HIW $\beta$ Jt; LTG $\beta \varepsilon t$; LHI $\beta æ t$; LYP $\beta \varepsilon t$; VLW $n-\beta \varepsilon t$; MTP $\beta \varepsilon t$; LMG $\beta \varepsilon$ ?; VRA $f \varepsilon ?$; VRS $\beta \varepsilon t$; MSN $\beta \varepsilon t$; MTA $\beta a t$; NUM fat; DRG $\beta a: t$; KRO $\beta \overparen{\varepsilon a t}$; OLR $\beta a t$; LKN $\beta æ s ;$ MRL $\beta \varepsilon t$.

Considering the phonetic diversity of the modern vowels in this correspondence set (4), it may seem impossible to reconstruct the phonetic value of the protovowel it is supposed to stem from. However, the solution can be found if other Oceanic languages are taken into the equation (François 2005). For example, the words for 'stingray' and 'four' are respectively ['fari] and ['fati] in 
Sungwadia, the language of northern Maewo (Agnès Henri, p.c.). These two forms show a word-final trochaic foot /CáCi/ where Torres-Banks languages have a single syllable CVC: e.g. Sungwadia fati corresponds to Lo-Toga $\beta \varepsilon t$. Many more examples could be cited, showing that the vowel correspondence set in (4) reflects a former trochaic foot ${ }^{\star}(\mathrm{C}) \dot{a}(\mathrm{C}) i$ that has undergone a process of umlaut, or metaphony. Even though modern reflexes are sometimes phonetically unexpected - as when Hiw reflects ${ }^{\star}(\mathrm{C}) \hat{a}(\mathrm{C}) \dot{i}$ with a rounded vowel - the processes are highly regular in each language. In other words, (4) above can be rewritten as the result of a historical process of sound change:

(4') $\quad$ *(C)á(C)i > HIW /Ј/; LTG / $\varepsilon /$; LHI /æ/; LYP /I/; VLW /I/; MTP / $\varepsilon /$; LMG / $/ \varepsilon /$ VRA / $\varepsilon /$; VRS $/ \propto /$; MSN $/ \varepsilon /$; MTA $/ a /$; NUM $/ \varepsilon /$; DRG $/ a: /$ KRO / $\overparen{\varepsilon a / ; ~ O L R ~} / a /$; LKN $/ æ /$; $\operatorname{MRL} / \varepsilon /$.

A similar reasoning holds for the second correspondence set in 'hibiscus' (3), yet with a different set of vowels, as listed in (6):

(6) Vowel correspondence set II:

HIW / /; LTG / /; LHI / $v /$; LYP /I/; VLW / $\varepsilon /$; MTP / $\varepsilon /$; LMG / $\varepsilon /$; VRA / $\varepsilon /$; VRS /œ/;

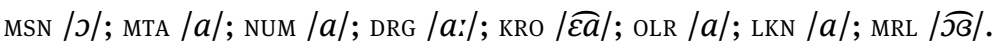

If we know that 'hibiscus' is fau in Samoan and valu in Gela of the Solomon Islands (Ross, Pawley, and Osmond 2008: 139), it is safe to conclude that the vowel set (6) reflects a former sequence ${ }^{\star}(\mathrm{C}) \hat{a}(\mathrm{C}) u$, which also went through umlaut, generally with back reflexes rather than front. Thus (6) can be rewritten as a historical process $\left(6^{\prime}\right)$ :

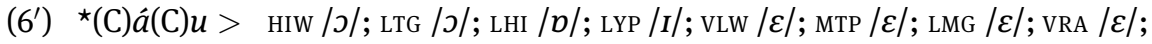
VRS /œ/; MSN /Ј/; MTA /a/; NUM /a/; DRG /a:/; KRO / $\overparen{\varepsilon a / ; ~ O L R ~ / a / ; ~ L K N ~ / a / ; ~}$ MRL $/ \overparen{J O} /$.

The same demonstration could be made for other combinations of the five protovowels - e.g. ${ }^{\star}(\mathrm{C}) \hat{a}(\mathrm{C}) e,{ }^{\star}(\mathrm{C}) o ́(\mathrm{C}) a,{ }^{\star}(\mathrm{C}) u ́(\mathrm{C}) i \ldots$ : each former trochaic foot is reflected by a single set of regular vowels similar to $\left(4^{\prime}\right)$ and $\left(6^{\prime}\right)$. François (2005) lists all regular correspondences, and shows that this process of umlaut or metaphony is the key to understanding the complexification of vowel systems in the area. Overall, the historical hypothesis of metaphony provides a powerful way to disentangle the phonetic history of the area, and retrieve regularity behind modern diversity. 


\subsection{Reconstructing protoforms}

By combining the regularities observed on consonants and on vowels, it is possible to reconstruct entire words. For example, if the cognate set $\{\beta: f . .$. reflects a protophoneme ${ }^{\star} \beta$ and $\left\{{ }_{L}: r: j \ldots\right\}$ reflects ${ }^{\star} r$, and if the hypothesis on vowels $\left(4^{\prime}\right)$ is correct, then the whole cognate set for 'stingray' (2) can be understood as the modern result of a set of regular sound changes that affected a single protoform ${ }^{\star} \beta a r i$. Using the same procedure, one can securely reconstruct

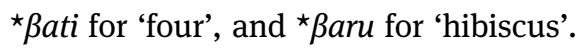

Once a protoform has been reconstructed, it can be represented as the source of a given cognate set. Thus, whereas (2) above was just a list of modern forms, $\left(2^{\prime}\right)$ entails a historical claim that all the forms are cognate, and that they reflect the specific protoform that is given as the header:

$\left(2\right.$ ') * Bari 'stingray' $\rightarrow$ HIW $\beta{ }^{g}{ }^{g}$; LTG $\beta \varepsilon r$; LHI $n-\beta æ j$; LYP $n-\beta I j$; vLW $n-\beta I j$; MTP $n \varepsilon-\beta \varepsilon j$; LMG $n-\beta \varepsilon r$; VRA $f \varepsilon r$; VRS $\beta œ r ;$ MSN $\beta \varepsilon r$; MTA $\beta a r$; NUM $f \varepsilon r$; DRG $\beta a: r$; KRO $\beta \widetilde{\varepsilon a r}$; OLR $\beta a j$; LKN $\beta æ ;$; MRL $n \varepsilon-\beta \varepsilon r$.

The forms for 'hibiscus' can similarly be subsumed under * $\beta a$ ru:

(3') * Baru 'hibiscus' $\rightarrow$ HIW $\beta{ }^{g}{ }_{L}$; LTG $\beta$ Jr; LHI $n-\beta v$; LYP $n-\beta I j$; vLW $n-\beta \varepsilon$; MTP $n \varepsilon-\beta \varepsilon j$; LMG $n-\beta \varepsilon r$; VRA $f \varepsilon r$; vRS $\beta \propto r$; MSN $\beta J r$; MTA $\beta a r$; NUM far; DRG $\beta a: r$; KRO $\beta \widetilde{\varepsilon a r}$; OLR $\beta a j$; LKN $\beta a ;$; MRL no- $\beta \widetilde{\partial O}$.

Each starred form constitutes a formula under which all modern forms, in spite of their current phonetic diversity, can thus be subsumed.

My current database includes about 650 lexical reconstructions; they are defined at a local level, that of "Proto Torres-Banks". These reconstructions capture the shared history of cognate words across the various languages of the area. In some cases, the etyma I propose have also been reconstructed at a higher level in the Oceanic tree (cf. Figure 3), with earlier phonological shapes (e.g. POc *paRi 'stingray', *paRu 'hibiscus', *pat 'four'). Thus ${ }^{\star}$ Bari in $\left(2^{\prime}\right)$ is nothing else than the form taken, in Proto Torres-Banks, by the POc etymon *paRi. In other cases, the proposed reconstruction has no other witness outside the Torres-Banks area, and therefore represents a local innovation. In the remainder of this chapter, I will usually mention when an etymon can be traced back to earlier times; otherwise, my reconstructions will be internal to the northern Vanuatu area. 


\subsection{Avoiding false etymologies}

Establishing the regular sound correspondences for each language in the area is crucial for the purpose of etymological research. This is a safe step in order to assess the cognacy between words that are potentially related, and avoid unwarranted hypotheses based on mere similarities or folk etymologies.

Let me take just one example. In Vurës, the form wol has two meanings: it is a noun meaning 'moon, month', and it is also a geocentric directional for short distances, along vectors parallel to the shore, pointing towards Southeast. It would have been tempting to suggest a connection between the two meanings: the space directional could originate, say, in the position of the moon at certain times of the year. However, such a hypothesis is ruled out by crosslinguistic comparison, provided one pays attention to regular sound correspondences. Vurës wrl 'moon, month' belongs to the cognate set in (7). Based on regular correspondences, the best reconstruction here is a proto-form ${ }^{\star} \beta u l a-$ itself a regular reflex of POc *pulan 'moon, month' (Ross, Pawley, and Osmond 2003: 158):

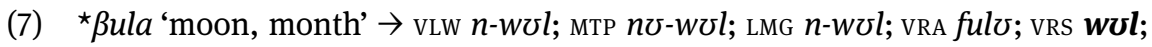
MSN wvl; MTA $\beta l a$; KRO $\beta \mho l$; OLR $\beta \mho l$; LKN $\beta \mho l$; MRL $n \mho-\beta \mho l$.

As for the Vurës directional wol, its equivalents in other languages of Vanua Lava present different vowels. Regular vowel correspondences point to an etymon *Bolo:

(8a) ${ }^{\star}$ Bolo $\rightarrow$ 'geocentric directional for short distances parallel to the shore, pointing Southeast': LMG wœel; VRA wøl; VRS wol; MSN wol.

Other northern Vanuatu languages reflect this root ${ }^{\star} \beta o l o$ as a reduplicated form * $\beta$ oloßolo, with various related meanings:

(8b) $\star$ ßoloßolo $\rightarrow$ 'sideways, across’: HIw wojwoj; MTA wolowolo.

(8c) ${ }^{\star}$ Boloßolo $\rightarrow$ [N] 'a crossbeam': MTP na-sal-wolwol; vRS wolvwvl; LKN wolwol.

(8d) ${ }^{\star} \beta o l o \beta o l o ~ \rightarrow[\mathrm{N}]$ 'a cross, incl. Christian cross; (astr.) the Southern Cross': MTP no-wolwol; MTA wolowolo; MRL no-wolwol.

The best reconstruction for the latter set $(8 \mathrm{a}-\mathrm{d})$ is a root * $\beta$ olo 'crossways, across' - and this is demonstrably the source of the directional in Vanua Lava languages (François 2010; in prep.). It so happens that the two sequences of 
syllables ${ }^{\star}(\mathrm{C}) \dot{u}(\mathrm{C}) a$ and ${ }^{\star}(\mathrm{C}) o ́(\mathrm{C}) o$ are both regularly reflected by the same vowel $/ \mho /$ in modern Vurës, which explains the homophony between wøl 'moon' $\left(<^{\star} \beta u l a\right)$ and wol 'Southeast' $\left(<^{\star} \beta\right.$ olo). Yet this is merely an accident of historical phonology, and any proposed connection between the two words would be a false etymology.

In sum, regular correspondences constitute a powerful touchstone when it comes to assessing the solidity of etymological hypotheses. The cautious comparison of modern forms, and the reconstruction of earlier protoforms, is the preliminary step before any reasoning about potential semantic connections becomes legitimate.

\subsection{Reconstructing semantic change}

The history of individual words sometimes involves sound change, yet little shift in meaning. For example, (7) above, reproduced below, does not involve any semantic change. Because the etymon's reconstructable meaning is identical with that of its modern reflexes, it is indicated only once, before the arrow $\rightarrow$ :

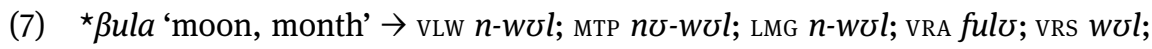
MSN wひl; MTA $\beta l a$; KRO $\beta \mho l$; OLR $\beta \mho l$; LKN $\beta \mho l$; MRL $n \mho-\beta \mho l$.

By contrast, when a shift in meaning must be reconstructed, the modern attested meaning is indicated after the arrow:

(8a) `ßolo 'crossways, across’ $\rightarrow$ 'geocentric directional for short distances

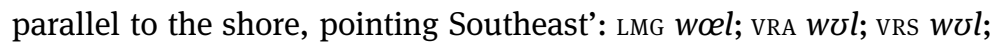
MSN wol.

These data sets only cite languages whose modern words reflect the protoform and display the meaning in question. When I only want to indicate the meaning of modern reflexes without making any claim about that of the protoform, then the gloss follows the arrow, as in (8d) below. When the semantic change also resulted in a change of syntactic category, I indicate the word's new part of speech in brackets (e.g. [N] for noun, [v] for verb, etc.).

(8d) ${ }^{\star} \beta$ olo $\beta$ olo $\rightarrow[\mathrm{N}]$ 'a cross, incl. Christian cross; (astr.) the Southern Cross': MTP no-wolwol; MTA wolowolo; MRL no-wolwol.

The remainder of this study will be focused on etymologies that involve some amount of semantic change. Along with their interest for understanding 
the languages and cultures of Island Melanesia, these results can feed into studies on the typology of semantic change, which are currently expanding (Traugott and Dasher 2002; Koptjevskaja-Tamm, Vanhove and Koch 2007; Vanhove 2008).

One methodological principle, in line with Blust (1987) or Ross, Pawley and Osmond (1998), consists in exploring a coherent semantic field so as to identify structural oppositions between different words within this domain. This will enable us, for example, to propose fine-grained nuances between words of similar meanings, such as the various etyma that can be reconstructed for designating the Underworld (§4.5.3).

As a methodological caution, I will endeavour to base every semantic reconstruction upon observable evidence. This will typically take the form of crosslinguistic comparison, whether within or without the northern Vanuatu area. The hypothesis of a semantic shift in one language can be strengthened by the existence of a similar shift, or a synchronic polysemy, in another language.

As a final illustration of the method, consider the set of forms in (9), used in modern languages to designate photographs:

(9) 'effigy, image, picture; (mod.) photograph'

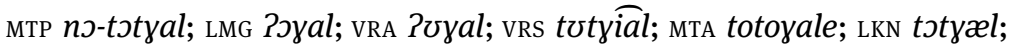
MRL $n \varepsilon$-tetyel.

The first step consists in ensuring, based on regular correspondences, that the forms are cognate: this is the case of all words in (9). Based on what we know of sound change in these languages, it is possible to reconstruct a protoform at the source of this set: this yields an etymon *totoyale. While this etymon is unknown elsewhere, ${ }^{4}$ its shape is reminiscent of two other words that can be reconstructed in northern Vanuatu: *toto 'chop, cut' (POc *totok) and * $y$ ale 'tell lies, pretend'. It appears difficult to find any convincing semantic link between 'chop', 'lie' and 'photograph', and any semantic hypothesis in this direction would seem far-fetched - unless it was backed up by convincing evidence.

In fact, the key to this etymology is provided by the technical terminology used by carpenters. In Mwotlap, while tot means 'chop, cut through 〈a piece of wood)', the serial verb tot zal, literally 'chop pretend', refers to the act of notching a piece of wood - i.e. 'cutting' it without chopping it all the way through. Modern Mwotlap speakers explicitly point out the semantic link between this

4 The words totoyale in Lo-Toga (Torres Is) and totokale in Teanu (Vanikoro, Solomon Islands; pers. data) both with the same meaning 'image, photograph', were evidently borrowed from Mota, at the time - late 19th century - when Mota was used by Anglican missionaries as the religious lingua franca of the area. 
technical term for notching wood and the traditional practice of carving out an effigy in wood or treefern, to make a sculpture or human representation. Obviously, the existence of this polysemy in at least one of the modern languages is a strong argument in favour of this etymological hypothesis regarding the whole cognate set:

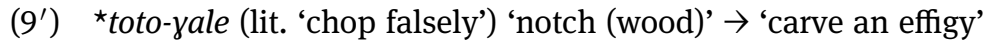

$\rightarrow[\mathrm{N}]$ 'effigy, image, picture; (mod.) photograph'

MTP no-totyal; LMG PJyal; VRA Poyal; vRs totyial; MTA totoyale; LKN totyæl; MRL $n \varepsilon$-tetyel.

The phonological form of the reconstruction is given for the level of "Proto Torres-Banks", the putative protolanguage from which modern reflexes can be derived. However, I make no claim about the historical depth of such a reconstruction. It is quite possible that the compound *totoyale is a relatively recent coinage, dating back perhaps just a few centuries, which spread through a portion of the dialect continuum. I also make no claim about the date of the semantic change (from a verb 'notch' to a noun 'image'), which could well have taken place recently and diffused across languages via contact. What I am really interested in is the fact that a set of modern forms can be safely shown to descend from a single etymon; and that the meanings associated with that cognate set can be shown to have evolved in a certain way during the history of these languages. In other terms, the main objective of this study is not so much to reconstruct a particular protolanguage ("Proto Torres-Banks"), as it is to unravel the history of individual words.

\section{The history of spiritual words in northern Vanuatu}

The previous section outlined the methodological principles that underlie the quest for reliable etymologies. The two pillars of this research are the solidity of sound correspondences, and the empirically assessed plausibility of semantic changes.

Based on these methodological principles, I here propose to explore the spiritual world of northern Vanuatu, via the words - and their derivatives that relate to notions of 'person', 'mind', 'soul', 'ghost' and other kinds of 'spirits'. Overall, I will mention about 80 concepts, providing each with a protoform and, whenever possible, with etymological comments. 
For reasons of space, I won't be able to mention all relevant words of modern languages, and will reduce my selection to those reconstructable words that are most significant, most revealing, or best represented in the Torres-Banks languages. Likewise, I will not be able to delve into all the ethnographic detail which would be ideally involved in dealing with such a rich domain. I shall restrict myself to those issues for which the linguist can make a contribution, and refer the interested reader to the abundant anthropological literature that revolves around the spiritual world of northern Vanuatu cultures - see, inter alia, Codrington (1891), Ivens (1931), Vienne (1984), Jolly (1996), LanouguèreBruneau (2002), Mondragón (2004), Hess (2009).

\subsection{The person}

\subsubsection{Terms for 'person'}

Along with the gender-specific terms for 'man' (see [16]-[17]) and 'woman' (see [1] above), Northern Vanuatu languages have a generic term for 'person (of unspecified gender)':

(10) 'individual, person, human being':

HIW taje; LTG tela; LHI $n$-at; LYP $n$-at; vLW n-at; MTP $n$-et; LMG $n$-Ppysor;

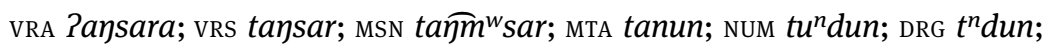

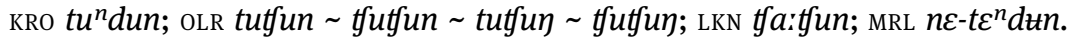

I will propose that all the forms in (10) ultimately derive from the same root, namely *ata 'person'. Four languages preserve this etymon as such, in their word for 'person':

(11) *ata 'individual, person, human being' $\rightarrow$ LHI $n$-at; LYP $n$-at; vLW $n$-at; MTP $n$ - $\varepsilon t$

This root *ata is the same word as POc * qata (Ross, Pawley and Osmond, in prep. b) and PNCV *?ata (Clark 2009: 76), which have been reconstructed with the same meaning 'person'. It is different from the homophonous root *qata meaning 'soul, spirit (of s.o.)' which I will discuss in §4.3.

Torres-Banks languages have a number of nouns with human referents whose first element is ${ }^{\star} t a-$. In principle, this ${ }^{\star} t a$ - prefix could reflect POc ${ }^{\star} t a u$, which also meant 'person'. But this is challenged by the observation that some derived forms reflect the retention of a vowel /a/ before the /t/ - e.g. Lehali 
$a t \eta^{w}$ an or Vurës $a t \overparen{\eta m}^{w}{ }^{w}$ 'man' as in example (16) below, or Lakon ætmæt 'ghost' (44), etc. This suggests that the apparent ${ }^{\star} t a$ - prefix should really be reconstructed as ${ }^{\star}$ ata-, with reflexes showing frequent apheresis and sporadic retention. Because the retention of the first vowel in *ata is the exception rather than the rule, I will henceforth represent the prefix as * $[a]$ ta-.$^{5}$ However, etymologically speaking, it is clear that this ${ }^{\star}[a]$ ta- prefix is the same root as the noun (11) *ata 'person'.

This prefixal element ${ }^{*}[a]$ ta- is found in the other forms of (10) with the generic meaning 'person'. Thus, several languages reflect an etymon which reconstructs as ${ }^{\star} \operatorname{ta}^{n} d u n u$ :

${ }^{\star} t^{n} d u n u \rightarrow$ 'individual, person, human being':

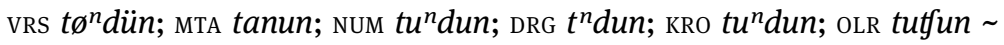

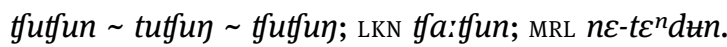

Even though the word has become unanalysable in modern languages, it was originally a compound form ${ }^{\star}[a] t^{-}{ }^{n} d u n u$, in which the second element ${ }^{\star n} d u n u$ meant 'true':

$$
{ }^{\star n} d u n u \text { 'true, real' } \rightarrow \text { vRS }{ }^{n} d \ddot{n} n \text {; MSN nun; MTA nun; NUM }\left.\beta i\right|^{n} d u n \text {; DRG }\left.l \varepsilon\right|^{n} d u n
$$

As pointed out by Codrington and Palmer (1896: 195), this etymon * $[a]$ ta- $^{n}$ dunu 'real person' stands in contrast with *[a]ta-mate 'dead person, ghost' (§4.4.1). In this part of the world, what defines a 'human being' is not the contrast with animals, but first and foremost its difference from ghosts and evil spirits. Note this is distinct from the common use, in other parts of the world, of 'real, true' as an ethnonym (e.g. Māori < māori 'true'): the latter pattern draws a contrast between the 'true' members of a social group and other human groups - a notion that is clearly absent from the meaning of * $[a]$ ta- ${ }^{n}$ dunu.

The four languages of Vanua Lava reflect a different protoform for 'person':

\footnotetext{
${ }^{\star}$ tam $^{w}$ asara $\rightarrow$ 'individual, person, human being':

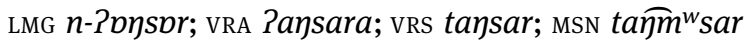

\footnotetext{
5 The use of square brackets follows established usage among Oceanicists (cf. Ross, Pawley and Osmond 1998: 13). Whereas round brackets refer to protophonemes whose presence in the etymon cannot be determined, square brackets symbolize the fact that two distinct reconstructions, one with and one without the bracketed element, can both be independently reconstructed based on modern evidence, and are equally robust.
} 
This form *ta-mwasara is also a compound, with the same base * $[a]$ ta 'person'. The second element ${ }^{\star} m^{w}$ asara is reminiscent of an adjective whose modern meaning is 'poor, needy':

(15) ${ }^{\star} m^{w}$ asara 'poor, needy' $\rightarrow$ LHI $\eta^{w}$ дsaj; LYP $\overparen{\eta m}^{w} a s a j$; LMG $\overparen{\eta m}^{w}$ psvr; мTP $\overparen{\eta m}^{w} a s a j$; мтА $\overparen{\eta m}^{w}$ asara; DRG $\widehat{\eta m}^{w}$ sar; LKN $\overparen{\eta m}^{w} a s a:$

Why would a compound 'poor person' become the normal word for 'person'? A tentative hypothesis could be that ${ }^{\star} m^{w}$ asara had a social meaning like 'commoner', and contrasted with a higher social class. Indeed, we will see that the antonym of ${ }^{\star} m^{w}$ asara, namely ${ }^{\star} m^{w}$ era-i somu 'rich', has lexical ties with the former political system, and with a class of highly ranked chiefs who were regarded as supernatural (\$4.7.1). By contrast, ${ }^{\star} t a-m^{w} a s a r a$ (lit. 'poor person') would have meant 'commoner, mundane person', before generalising as the default term for 'person'.

The two Torres languages show two forms (HIw tajo; LTG tela) which seem to reflect a protoform ${ }^{\star}$ tala or ${ }^{\star}$ talua. While these seem to include the same ${ }^{\star} t a-$ prefix, the etymology of the whole compound is unclear (but see fn. 9).

\subsubsection{The question of gender}

The element ${ }^{\star}[a] t a$, which we just saw in compounds with the generic meaning 'person', can also be detected in various compounds referring to humans. Some of these compounds raise the question of whether *ata was really unspecified for gender, or typically associated with male referents.

The word for 'male, man, husband' can locally be reconstructed as a protoform * $\left[\right.$ a]tam ${ }^{w}$ ane:

(16) $*[a]$ tam $^{w}$ ane $\rightarrow$ 'male, man, husband':

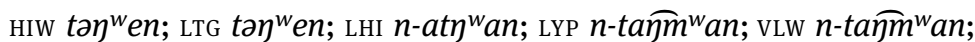

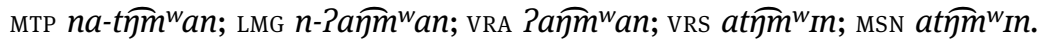

This form reflects a PNCV compound *(2)ata-mwa?ane (Clark 2009: 76), in which the second element reflects POc *maRuqane 'male' (Blust 2012) or its doublet ${ }^{\star} m^{w}$ aqane (Ross, Pawley and Osmond in prep.). In this word, the gender information can be attributed to this second element, and the prefix * $[a]$ ta- may still be analysed as gender-neutral: * $[a]$ ta- $m^{w}$ ane literally parses as 'person-male'.

The situation is a bit different in the southern Banks languages, which have lost $*[a]$ ta- $m^{w}$ ane. They have replaced it with a new compound (17) 
${ }^{\star} m^{w}$ era-i ata, in which the second element is again *ata 'person'. As for the first element, it is a noun ${ }^{\star} m^{w}$ era 'child' (François 2011a: 185; Clark 2009: 155). Literally, the compound ${ }^{\star} m^{w}$ ereata can be interpreted as 'child of a person'; it likely referred originally to a 'boy child' (opp. 'girl'), and later generalized as 'male, man'.

${ }^{\star} m^{w}$ era-i ata 'child of a person' $\rightarrow{ }^{\star} m^{w}$ ereata 'male, man, husband': MTA $\overparen{\eta m}^{w}$ ereata; NUM $\overparen{\eta m}^{w} \varepsilon r a t$; DRG $\overparen{\eta m}^{w}$ crat; KRO $\overparen{\eta m}^{w}$ arat; OLR $\overparen{\eta m}^{w}$ arat; LKN $\overparen{\eta m}^{w} \varepsilon: r a t ;$ MRL na- $\eta^{w}$ arat.

In Mota, the singular form $\widehat{\eta m}^{w}$ ereata 'man' has a suppletive form for plural: rereata 'men' - itself a compound of rere 'Plural' and * ata 'person'. It is worth of notice, again, that phrases that are apparently unspecified for gender, such as 'child of a person', or 'PLURAL:person', have lexicalized with specifically male referents. In the case of ${ }^{\star} m^{w}$ ereata, the gender shift is to be assigned not so much to *ata as to the first element ${ }^{\star} m^{w}$ era 'child' $\rightarrow$ 'boy child, son'.

It is not the case, however, that all reflexes of *ata are specifically male. The prefix * $[a]$ ta- is also found on the Mota form for 'woman, female', namely taßne - from *ta-ßine 'person-woman' [see (1) above]. Lo-Toga has a reflex of the same form but with a different meaning, təßina 'mother-in-law'. Both reflect a POc compound *qata-pine 'woman, female', from * $(p a)$ pine with the same meaning (Ross, Pawley and Osmond, in prep. b).

The gender ambiguity is also observable in the pronoun forms that were created in some languages, and which also contain *ata. The two Torres languages have thus developed a set of pronouns that code for number and gender. Even though *ata, as an etymon, is normally gender-neutral, it is only present in the masculine forms of these pronouns: HIW $t \theta^{g} L \mid$ atə $=$ LTG hori $\mid$ atə (masculine dual) 'two men'.

Conversely, Lakon has a small paradigm of anaphoric pronouns that include * ata as a second element (the first element is the 3rd person pronoun): wซrv-at 'these two people', trlis-at 'these three people', yr:-at 'these people'. Although these forms are in principle neutral in gender, they contrast with another set

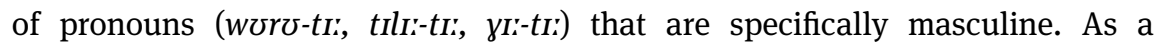
consequence of this asymmetry, the neutral forms ending in -at tend to be more frequently associated with female referents.

In sum, the root ${ }^{\star}$ ata must be reconstructed as neutral in terms of gender, even though some its reflexes have become specifically associated with male or with female referents. 


\subsubsection{Other terms derived from *ata 'person'}

Northern Vanuatu languages have a noun *tamarayai referring to an 'old man'. As a noun, this word is normally specifically male - contrasting with *mayatea 'old woman' - but as an adjective, it can be used for any gender, meaning 'old':

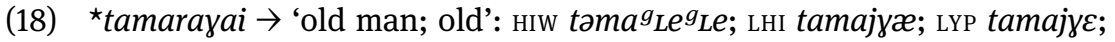

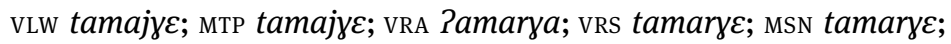
MTA tamarayai; NUM tamaraya; DRG tmarya; LKN tama;yæ; MRL temerye

This word is an interesting compound, based on the * $[a]$ ta- element. The second element is reminiscent of a word that has a very different meaning, namely 'shy, ashamed'. The semantic connection is opaque, until one realizes that the words in (19) did not initially mean 'shy', but were really a verb 'tremble, quiver' (Codrington and Palmer 1896: 72):

(19) $\star$ [ma]marayai 'tremble, quiver' $\rightarrow$ 'shy, ashamed, shameful':

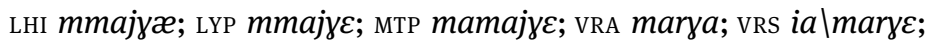
MTA marayai; NUM maraya; DRG marya; LKN ma:yæ

An old man (18) is thus *[a]ta-marayai 'a quivering person'. As for the notion of shyness, it is in fact a construction in which the subject is a noun * $a^{m} b e$ 'body'; so, 'I feel shy' is literally 'my body is quivering'. Finally, the same root *marayai 'quiver' can be found in Mwotlap mat-majyc 'sleepiness' - etymologically *matamarayai 'quivering eyes'.

Another word referring to an 'old person' (of any gender) is *tamatua:

${ }^{\star}$ tamatua $\rightarrow$ 'old person': HIw taməso; LTG teməto; мTA tamatua

This word is a compound of * [a]ta- 'person' and *matua 'ripe, mature' (> HIw maso 'ripe, fullgrown; large') - itself from POc *matuqa 'ripe, mature, fullgrown'. The metaphorical connection between a ripe fruit and old age is evidently an ancient one, as it is reflected in many Oceanic languages (Ross, Pawley and Osmond 2003: 204).

I will later cite the compound (86) *ta- $\beta$ usi-mwele 'man of high rank' (§4.7.2), also derived from * $[a]$ ta-. Finally, a last compound based on that root is * $[a]$ tamate 'dead person, ghost, ancestral spirit'. This important word will be the focus of $\$ 4.4$ below. 


\subsection{The mind}

The notion of someone's mind or psyche is covered by a number of different terms in northern Vanuatu languages, and I will only cite a few of them here.

Sometimes, the word ${ }^{\star m} b^{w} a t u$ 'head' $\left(<\mathrm{POc}{ }^{\star m} b a t u\right)$ is used to refer to one's intelligence. I here give the form with the 1 sg possessor $\left({ }^{\star}-{ }^{-} g u\right)$ :

${ }^{\star m} b^{w} a t u\left(-{ }^{\eta} g u\right)$ '(my) head' $\rightarrow$ '(my) head; (my) intelligence':

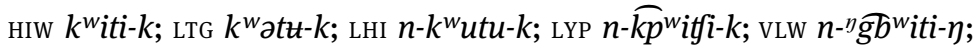

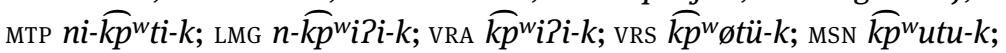
мта $\widehat{k p^{w}} a t u-k$; NUм na- $\widehat{k p}^{w} u t u-k$; DRG na- $\widehat{k p}^{w} t u-k$; кRо $\widehat{k p^{w}} u t u-k$; оLR $\widehat{k p}^{w} u t u-k$; LKN $k^{w}{ }^{w} a t \mho-k$; MRL $n o-k^{w} G t u-k$

An example would be Mwotlap ni- $\widehat{k p}^{w} t i n \varepsilon-h \varepsilon j$ 'you have a sharp mind' (lit. 'your head is sharp'); or ni-kpw ti na-wak 'you're open-minded, you have a curious mind' (lit. 'your head is open'). For these intellectual senses, Mwotlap can also use nv-svl 'brain' and nI-mina-n 'fontanelle', yet these do not seem to be frequently used in other languages of the region. Torres-Banks languages occasionally describe certain feelings using other body parts - such as the 'diaphragm' ( $\left.{ }^{\star} m^{w} a l a\right)$ for surprise; the 'belly' $\left({ }^{\star} t o^{m} b^{w} a\right)$ for desire; the 'liver' ( $\left.{ }^{\star} \beta a r a\right)$ for awe and fear. For reasons of length, I shall not illustrate these senses here.

The most common term when referring to the mind and to certain emotions are reflexes of an inalienable noun which can be reconstructed as ${ }^{\star} l o l o$. With a 1 sg possessor, the suffixed form reconstructs as ${ }^{\star} l o l o-{ }^{n} g u:{ }^{6}$

${ }^{\star} \operatorname{lolo}(-\eta g u) \rightarrow$ '(my) mind, will....'

HIW $j \theta-k$; LTG lio-k; LHI $n$-lI- $k$; LYP $n$-lø-k; vLW $n$-lI- $\eta$; MTP na-lI- $k$; LMG $n$-lø-k; VRA lv-k; VRS lølø-k; MSN lvlv-k; MTA lolo-k; NUM na-llo-k; DRG na-llv-k; KRO na-llv-k; OLR lvlv-k; LKN lolo-k; MRL $l \theta-k$

This noun is slightly atypical. While it behaves morphologically like a body part (obligatory presence of possessor), it cannot be located anywhere on the body. It never appears in the position of object or adjunct (as in Eng. in my mind), and is restricted to subject position. Furthermore, in each language it can only take a small number of predicates. For example, in Mwotlap, na-lI-k is only used as

6 The simplification of geminates (e.g. *nà loló- ${ }^{\prime} g u>{ }^{*} n a-l l 1-k>n a-l l-k$ ) is regular in Mwotlap (François 2000a: 59-60) and other northern languages. 
the subject of $m[\varepsilon] j \varepsilon n$ 'daylight' and $\widehat{k p^{w}} \mho \eta$ 'night', in constructions that mean respectively 'remember; be lucid' and 'forget; be unconscious':?

\begin{tabular}{|c|c|c|}
\hline МтР & $\begin{array}{l}n a-l \bar{e}-k \\
\text { /na-li-k }\end{array}$ & $\begin{array}{l}\text { me-myen } \\
\text { me-mjen }\end{array}$ \\
\hline & ART-mind-1sg & PRF-daylight \\
\hline
\end{tabular}

$$
\begin{aligned}
& \text { Mтр na-lo-n may qōn. } \\
& \text { /na-lo-n maj } \mathrm{kp}^{\mathrm{w}} \mathrm{vn} / \\
& \text { ART-mind-3sg CPLT night }
\end{aligned}
$$

'He has already forgotten (it)' 'He’s unconscious' 'He’s senile.'

Given these sentences, a language-internal analysis of Mwotlap may define $n a-l_{-}-k$ as 'memory' or 'consciousness'. And indeed, modern speakers have no other gloss for it: the $n a-l_{I-k}$ is simply 'that thing in you that gets dark when you forget, and illuminated when you remember'. Notice, in passing, the metaphor of light that is also found in the etymologies of English lucid, enlighten, illuminate or brilliant.

But the observation of cognate forms in languages other than Mwotlap makes it clear that the underlying meaning of *lolo must be broader than just 'memory'. While they all share with Mwotlap the constructions illustrated in (23)-(24), they also use the forms in (22) in constructions referring to anger. Depending on the language, the possessed noun is then the subject of an adjectival predicate *saat[i] 'bad' (Lemerig in [25]); or of a verb *anu 'sting, irritate' (Vurës in [26]):

$$
\begin{aligned}
& \text { lö-k se' sā n-īmeri now. }
\end{aligned}
$$

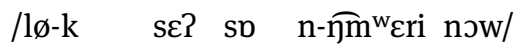

$$
\begin{aligned}
& \text { mind-1sg bad } \text { FOC }_{1} \text { ART-child that:FOC } 2 \\
& \text { 'I'm angry at that child' (lit. 'My mind is bad (at) that child') }
\end{aligned}
$$

7 Sentential examples in individual languages are provided in standard orthographies, followed by a phonemic transcription. Abbreviations in glosses include: ART article; CPLZR complementizer; CPLT complete aspect; DEP dependent clause; FOC focus marker; FUT future; РОт potential; PRF perfect; $P R O H$ prohibitive. 
(26) VRS nitog na lolo- $\bar{n}$ ge en no!

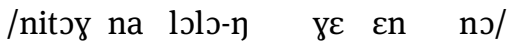

PROH ART mind-2sg FUT sting 1sg

'Don't be mad at me!'

(lit. 'Don't let your mind sting me')

Somewhat more figuratively, several languages use a verb ${ }^{\star n}$ goto 'nip, bite' (Lakon in [27]) or * yara 'bite' (Mwesen in [28]):

(27) LkN lolo-̄̄ mētē kot lee na!

/lolo-n miti kot le: na/

mind-2sg $\mathrm{PROH}_{1}$ nip $\mathrm{PROH}_{2}$ 1sg

'Don't be mad at me!'

[lit. 'Don’t let your mind nip me!']

(28) MsN lōlō-k mete gagar le nēk.

/lvlv-k mete yayar le nik/

mind-1sg NEG: $\mathrm{POT}_{1}$ bite $\mathrm{POT}_{2}$ 2sg

'I won't be angry at you.'

[lit. 'My mind won't bite you']

Finally, the two Torres languages employ *lolo as the subject of a verb 'want, like' - as in Hiw (29):

(29) Hiw ne yö-k ñis tom ke tō ver̃og.

/nə je-k nis tom kə to $\beta \partial^{\mathrm{g}} \mathrm{L} \partial \mathrm{\gamma} /$

ART mind-1sg want CPLZR 1sg:DEP go:SG also

'I want to go too.' [lit. 'My mind wants that I go.']

In sum, the meaning of *lolo includes not only reference to the 'memory', but also to the seat of will and emotions - at least anger. The abstract gloss 'mind' reflects this semantic versatility.

Crucially, it is possible to identify the etymology of the word *lolo which is here glossed 'mind'. This is historically the same word as *lolo 'inner part, interior' which otherwise designates the inside of an inanimate object, e.g. a house. Because this spatial use of 'inside' is normally incompatible with human possessors, speakers of at least some languages perceive the two constructions as involving separate words. For instance, my Mwotlap consultants never drew a connection between /lo/ in na-lo I $\overparen{I m}^{w}$ 'the interior of the house' and /li/ in (23) 
na-lI- $k$ 'my memory'. This is partly due to morphological processes of ablaut e.g. 1sg /li-k/, 3sg /lo-n/ - which have blurred the link between otherwise cognate forms (François 2005: 485). Only cross-linguistic comparison made it obvious that the word for 'mind' is really the same word as 'interior' - via a metaphor we have in English with inner thoughts or inner man. The same polysemy is found elsewhere in the Austronesian family, whether associated with the same POc etymon *lalo $[\mathrm{m}]$ 'inside, inner part; mind, feelings' like here in northern Vanuatu; or with POc *loto 'inner self, feelings, mind' (Blust 2012).

Finally, the identification of an etymon *lolo 'interior, inside (of s.th.); mind (of s.o.)' makes it possible to unravel the etymology of a whole set of compounds based on this noun. They all follow a pattern in which *lolo is an incorporated subject, followed by its predicate; the output of this composition can be a verb, an adjective or a noun. For example, *lolo- 'interior, mind' and ${ }^{\star} m b^{w}$ oni 'night' (<POc $\star^{\star m}$ boni) form together a compound ${ }^{\star} l o l o-{ }^{m} b^{w}$ oni (lit. 'mind in night'). As a verb, the form means 'forget'. As an adjective, it translates as 'stupid, ignorant' (cf. Eng. benighted) or sometimes 'crazy'. As a noun, it refers to 'heathen times' before Christianisation.

(30) *lolo- ${ }^{m} b^{w}$ oni 'mind in night'

$\rightarrow$ '[V] forget; [ADJ] stupid, ignorant, foolish; [N] heathen times':

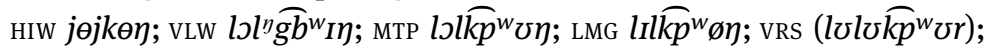

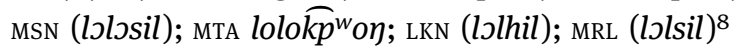

Thus $\left(24^{\prime}\right)$ is essentially an equivalent of (24) above, in the same language Mwotlap:

$$
\begin{aligned}
& \text { MтP kē may lol-qōn. }
\end{aligned}
$$

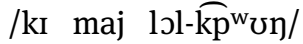

$$
\begin{aligned}
& \text { 3sg CPLT mind-night } \\
& \text { 'He has already forgotten (it).' }
\end{aligned}
$$

The antonym of ${ }^{\star}$ lolo- ${ }^{m} b^{w}$ oni is ${ }^{\star}$ lolo- $+{ }^{\star}$ marani 'daylight' $\left(<\mathrm{POc}{ }^{\star}\right.$ raqan 'day'). The sentence (23) above already illustrated how the noun *lolo- can be the subject of a predicate *marani 'daylight': the phrase resulted in a meaning 'remember'. The compound *lolo-marani, although based on the same elements, takes up a meaning of its own:

8 Forms in brackets are compounds that follow the same pattern, but have replaced the

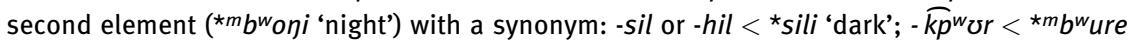
'ignorant'. 
(31a) *lolo-marani 'mind in daylight'

$\rightarrow$ '[ADJ] wise, intelligent, knowledgeable; [N] wisdom, knowledge':

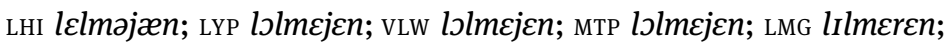

VRA lolmaran; VRS lolvmeren; MSN lJlmeren; MTA lolomaran; DRG llJmra:n;

LKN lJlma:ræn; MRL lolmeren

In the two Torres languages, the reflexes of this etymon have become the verb 'know':

(31b) *lolo-marani 'mind in daylight'

$\rightarrow$ '[ADJ] wise, intelligent, knowledgeable; [N] wisdom, knowledge;

[v] know':

HIW jejma ${ }^{g}$ Len; LTG lolmaren

The semantic differences between the phrasal constructions and the lexical compounds are summarized in Table 1.

\begin{tabular}{|c|c|c|}
\hline & *lolo 'mind' + *mbwoni 'night' & *lolo 'mind' + *marani 'daylight' \\
\hline $\begin{array}{l}\text { PHRASE } \\
\text { (Subject + Predicate) }\end{array}$ & forget; be unconscious; be senile & remember; be lucid \\
\hline Compound & $\begin{array}{l}{[v] \text { forget; }[A D J] \text { ignorant, foolish; }} \\
{[N] \text { heathen times }}\end{array}$ & $\begin{array}{l}\text { [ADI] wise, intelligent, knowledgeable; } \\
{[\mathrm{N}] \text { wisdom, knowledge; }} \\
{[\mathrm{v}] \text { know }}\end{array}$ \\
\hline
\end{tabular}

Table 1: Meaning of some phrases vs compounds involving *lolo 'inside; mind'

One also finds various *lolo- compounds referring to anger:

(32) *lolo-saat [i] 'mind bad' $\rightarrow$ '[ADJ] angry; [N] anger': LTG lolhia; LHI lelsæt; LYP lolsit; LMG lilse?; VRA lvlse?

(33) *lolo-'ygoto 'mind nip' $\rightarrow$ '[ADJ] angry; [N] anger': DRG lolkJtkJt; OLR lolkJtkJt; LKN lolkJt

(34) *lolo-yara 'mind bite' $\rightarrow$ '[ADJ] irritated, angry; [N] anger, irritation': мTP lolyayaj; vRs lolyayar; мTA loloyara

(35) *lolo-anu 'mind sting' $\rightarrow$ '[ADJ] irritated, angry; [N] anger, irritation': VRs lolenen; MTA loloanu; MRL lolon 
Finally, the languages of the area have two other compounds:

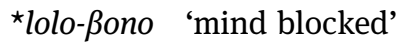

$\rightarrow$ '[ADJ] sad, sorrowful, melancholic; [N] sorrow':

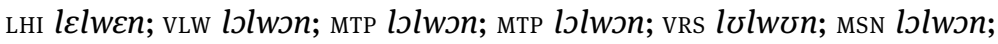
MTA lolowono; NUM lolJwon; DRG lJlwon; LKN lolwon; MRL lolwon

(37) ^lolo-wia 'mind good' $\rightarrow$ '[ADJ] kind, thankful; [INTERJ] thanks': HIW jejwja; LTG lowia; MTA lolowia; MRL lolw $\overparen{\varepsilon a}$

Much more could be said on the lexical domain of psychology and feelings, but this would require a detailed semantic analysis of each language separately, and would take us beyond the scope of this study. Suffice it to say that the most widespread etymon referring to the 'mind' in northern Vanuatu is *lolo etymologically 'inside'.

\subsection{The soul}

The term *lolo 'inside; mind' is only used about living, sentient individuals. The same languages employ different, unrelated words to express the notion of 'soul' - that is, the living part of a person separable from the body. The domain of the soul will lead us to explore a new territory - namely, the world of ghosts and spirits.

Importantly, the words cited in this section are never used to refer to the mind or psyche of a living individual, as in English deep in my soul or a sensitive soul. Contrary to many languages in which these notions are etymologically related,9 'mind' and 'soul' are two separate notions in Vanuatu languages, which have nothing in common, and are never used in the same contexts. The notion of 'soul' is mentioned exclusively in those contexts where the living part of an individual is said to separate from their body, and move to other locations.

The cultures of northern Vanuatu mention three kinds of contexts when this sort of separation takes place. First, when somebody dies, their soul will separate from their body, and hover close to it for about five days (Hess 2009: 161), until it starts its voyage towards the Other World (see §4.5). Another occasion is when a victim of sorcery becomes deeply sick or insane: this is because their soul has been kidnapped by evil spirits, and needs to be brought back to their body. The third occasion when souls are mentioned corresponds precisely to the magic

9 Cf. Latin animus and anima, or the various senses of spīritus, of Sanskrit ātman, Arabic rūh, etc. (François 2008b: 187-213). 
practice of healers or shamans: they are the ones who can get their own soul to wander between worlds while their body is asleep. This power allows them, for example, to travel across to the Other World, and bring back the soul of the sick person they want to heal (see [40], [77] below).

\subsubsection{POC *qata: one or two roots?}

In several languages, the word for 'soul' is a noun *ata - a homophone with the other word *ata 'person, human being' we saw earlier (11). One morphological difference, though, is that *ata 'soul' is an inalienable (relational) concept, which obligatorily indexes a possessor ('soul of s.o.'). The latter normally takes the form of a possessive suffix, which is here given in its 3 sg form ${ }^{\star}$-na:

$$
\begin{aligned}
& \text { *ata (-na) '(his/her) soul, spirit' } \\
& \quad \rightarrow \text { HIW ata-nə; LTG te-nə; LHI } n \text { - } \varepsilon t a-n \text {; VRs ata-n; MTA ata-na. }
\end{aligned}
$$

In terms of historical morphology, it is relevant to note that the suffixation entailed a shift in stress, which occasionally altered the quality of some vowels. Thus for the single language Lehali, compare ${ }^{\star}(n a)$ áta $>n$-at 'person' with *(na) atá-na $>n$-cta-n 'his/her soul'. In Vurës, former processes of umlaut (see §3.1), combined with vowel harmony, have triggered stem alternations: *atá-"gu > VRS œetœ-k 'my soul'; *atá-na > ata-n 'his/her soul'; *atá-i > $\varepsilon t \varepsilon$ 'soul of' (François 2005: 484-488). As for the sequence (C)e(C)ə in Lo-Toga, it is the regular reflex of an earlier string *(C) $a(\mathrm{C}) a$ (François 2005: 490).

Proto Torres-Banks *ata 'soul, spirit' is the same word as PNCV ${ }^{\star}$ ?ata, whose sense 'soul, spirit' is found in other languages of Vanuatu (Clark 2009: 76). The three languages of Vanikoro, in the Solomon Is, also reflect it: Teanu ata, Lovono ala, Tanema ae 'soul, spirit' (François 2009: 111). Cognate forms in other Oceanic languages have a meaning 'shadow, reflection', as in Tongan Pata (Ross, Pawley and Osmond, in prep.) - a sense which is lexified differently in north Vanuatu. All this points to the reconstruction of a POc form ${ }^{\star}$ qata 'shadow, reflection; soul, spirit'.

It is not entirely clear whether POc * qata 'person, human being' and POc * qata 'shadow, reflection; soul' formed a case of polysemy of a single word - or if they were mere homophones. The semantic connection between 'person' and 'soul, essential living component of a person' does not seem implausible, and one could propose that the two roots may be ultimately the same word. However, a discussion with several specialists of the domain (R. Blust; A. Pawley; M. Ross; M. Osmond, p.c.) yielded the conclusion that POc *qata is more 
probably a case of homophonous terms arising from different sources (see also Osmond, this volume). Table 2 sums up the steps that can be reconstructed for the shifts in meaning and sound of the two roots, which are further commented upon below.

\begin{tabular}{|c|c|c|c|c|c|c|}
\hline & PAN & Pre-POc & POC & PnCV & $\begin{array}{l}\text { Torres- } \\
\text { Banks }\end{array}$ & e.g. Lehali \\
\hline 'outsider, alien' & ${ }^{*}$ qaRta $>$ & $\begin{array}{c}\text { *qata } \\
\downarrow\end{array}$ & & & & \\
\hline 'person' & & ${ }^{*}$ qata $>$ & ${ }^{\star}$ qata $>$ & *?ata $>$ & ${ }^{*} a t a>$ & (11) $n$-at \\
\hline 'shadow, reflection' & ${ }^{*}$ qantad & $>$ & $\begin{array}{c}* \text { qata } \\
\downarrow\end{array}$ & & & \\
\hline 'soul, spirit' & & & ${ }^{\star}$ qata $>$ & *Pata > & ${ }^{*} a t a>$ & (38) $n-\varepsilon t a-n$ \\
\hline
\end{tabular}

Table 2: The two homophones *qata of Proto Oceanic

The starting point for the first etymon is a Proto Malayo Polynesian root * qaRta, which Blust (1972, 2012) reconstructs as ‘outsider, alien'; it shows a shift to 'human being, person' even before Proto Oceanic, in various Central MalayoPolynesian languages (Blust 2012). At the level of POc, the form had changed to * qata, and the original meaning 'outsiders, alien people' had evidently been lost, as it is attested nowhere in Oceanic languages; the word had broadened its meaning to 'person, human being', for which * qata then competed with *tau (Ross, Pawley and Osmond, in prep.). The Banks and Torres forms cited in (11), illustrated in Table 2 with Lehali, reflect regular sound change from * qata.

As for the second *qata, it has been linked (Ross, Pawley and Osmond, in prep.) with a PAN root * qantad 'shadow, reflection, image, likeness' (Dahl 1981). The semantic connection between 'soul, spirit' and 'shadow' is relatively widespread in the Austronesian word, whether in relation to this root *qata or with POc ^qanunu 'shadow, reflection, soul' (Blust 2012). Common to all these notions is the reference to a person's particular "presence", when it contrasts with the physical reality of their body. The spirits of our ancestors are present amongst us, in our personal memories and in our collective representations like the shadows of bygone lives.

\subsubsection{A second etymon for 'soul'}

Besides the form *qata given in (38), some Banks languages lexify 'soul, spirit' with a different protoform *tala (-na): 
`tala $(-n a) \rightarrow$ '(his/her) soul, spirit'

LYP $n$-tala- $n$; vLW $n$-tala-n; MTP na-tala- $n$; LMG $n$-Palb- $n$; LKN tala/tI- $n$

The origin of *tala is unclear. It may ultimately be derived from *ata (?), plus an element ${ }^{*}$-la- of unknown origin. ${ }^{10}$

My Mwotlap informants were specific about what has a soul and what does not. Plants, as well as smaller animals such as insects, mice, or fish, are not endowed with a soul. By contrast, higher animates have a soul, including pigs (an important animal in traditional society), whales, dolphins, and the dreaded sea-snakes - but not sharks or turtles. ${ }^{11}$

This root *tala can be found in the compound *tala-mauri - literally 'soul alive' ( $<$ POc *maqurip 'live, alive'). This refers to a magical practice whereby a person endowed with supernatural powers ( ${ }^{\star}$ mana, see (90) below) is capable, while their body is asleep, of letting their own soul migrate and wander between worlds, for a few hours, before returning to the body. This practice can have a specific purpose - e.g. the magician is a healer who needs to migrate to the realm of the dead, in order to fetch the soul of a sick person - or may be purely gratuitous. ${ }^{12}$

(40a) `tala-mauri 'soul alive' $\rightarrow$ 'a magical practice whereby the soul of a living healer wanders away from their body’: мтР na-talmij

Codrington and Palmer (1896: 189) has a slightly different definition for the cognate form in Mota:

(40b) *tala-mauri $\rightarrow$ 'one whose soul goes out to eat the soul of a dead person': MTA talamaur

The etymology 'soul alive' is presumably grounded on the fact that this magical practice is carried out by a living person, who has the power to bring the soul back to the body; this is in contrast with the final migration of one's soul out of the body, which follows death. The realm of souls and ghosts is precisely the object of the next section.

10 It is possible, though hard to confirm, that this *ala may be the same form underlying the Lo-Toga noun for 'person', tela < *tala (\$4.1.1).

11 Note, however, that reports sometimes vary on these matters (Lanouguère-Bruneau 2002: 220).

12 We will see below a related notion *[a]tamate-rono (77). 


\subsection{The names of ghosts and spirits}

\subsubsection{On life and death}

The stages of life and death are expressed respectively by two verbs: *esu and *mate.

(41) `esu 'live, be alive' $\rightarrow$ HIW (at); LTG (ah); LHI Ih; LYP Is; VLW Ih; MTP Ih; LMG Is; VRA IS; VRS IS; MSN IS; MTA eS; NUM IS; DRG IS; KRO IS; OLR IS; LKN IS; MRL IS

This form *esu is a local innovation; the POc etymon *maqurip 'live' only survives in a few compounds, as in (40) above. By contrast, the word for 'die' is conservative of $\mathrm{POc}{ }^{\star}$ mate:

(42) *mate 'die, be dead' $\rightarrow$ HIW met; LTG met; LHI mat; LYP mat; vLW mat; MTP mat; LMG ma?; VRA ma?; VRS miat; MSN mat; MTA mate; NUM mat; DRG mat; KRO mat; OLR mat; LKN mæt; MRL met

This verb ${ }^{\star}$ mate was nominalized into ${ }^{\star}$ matea $\left(<\mathrm{POc}{ }^{\star}\right.$ mate-an). Reflexes of this noun refer to the funeral ceremonies that occur after someone died, whether this refers to their burial, or to the mourning rituals that take place five, ten and fifteen days after the death:

(43) `matea $\rightarrow$ 'death; funeral ceremonies: burial, mourning rituals':

HIW mase; MTP na-mte; LMG mæ?æ; VRS matI; MTA matea; DRG mte mata-n;

KRO mata-n; LKN meta-n; MRL na-matI

One of the functions of the mourning rituals is to allow the soul of the dead person to leave this world, and start its journey towards the Underworld. At this point, people no longer refer to the 'soul' ( $\left.{ }^{\star} a t a\right)$ of the person, but to their 'ghost' (Hess 2009: 162). The etymon for 'ghost' reconstructs as *atamate. In most languages, the form has undergone apheresis ( ${ }^{\star}$ atamate $>{ }^{\star}$ tamate), a phonological process common in the area; yet the Lakon form ætmæt makes it necessary to posit an earlier form starting in *ata. Following the same reasoning as earlier for its first element *[a]ta- (\$4.1.1), I choose to represent the etymon as *[a]tamate: this reflects the fact that while some languages point to a longer form *atamate, others unambiguously reflect a truncated form *tamate.

The word is historically a compound *[a]ta-mate, literally ‘dead person’:

(44) *[a]ta-mate 'dead person, ghost + '

$\rightarrow$ HIW tamet; LTG tamet; LHI $n$-tamat; LYP $n$-tamat; vLW $n$-tamat; мTP na-tmat; LMG Pama?; VRA Pama?; vRs timiat; MSN tamat; мTA tamate; NUM tamat; DRG tmat; KRO tamat; OLR tamat; LKN ætmæt; MRL ne-temet 
While the first element ${ }^{\star}[a]$ ta- has become opaque in modern languages, it is often easy for modern speakers to draw a connection with the word 'dead' (42). Note that it is ambiguous whether the first element of this compound is here (11) *ata 'person', or (38) *ata 'soul, spirit'. The common assumption is to opt for the first interpretation, as witnessed by the POc reconstruction *qata-mate glossed 'dead person' (Ross, Pawley and Osmond, in prep.). But the northern Vanuatu area leaves the ambiguity open.

\subsubsection{The polysemy of *[a]tamate}

Yet the main interest of (44)*[a]ta-mate lies less in its etymology - which is mostly transparent - than in the impressive polysemy it displays in northern Vanuatu languages. While most languages of the area share the same extensions, some have gone further than others. Figure 4 represents the various meanings that can be lexified by modern reflexes of $*$ a]tamate. It takes the form of a lexical semantic map, in the spirit of Pawley (2005) or François (2008b).

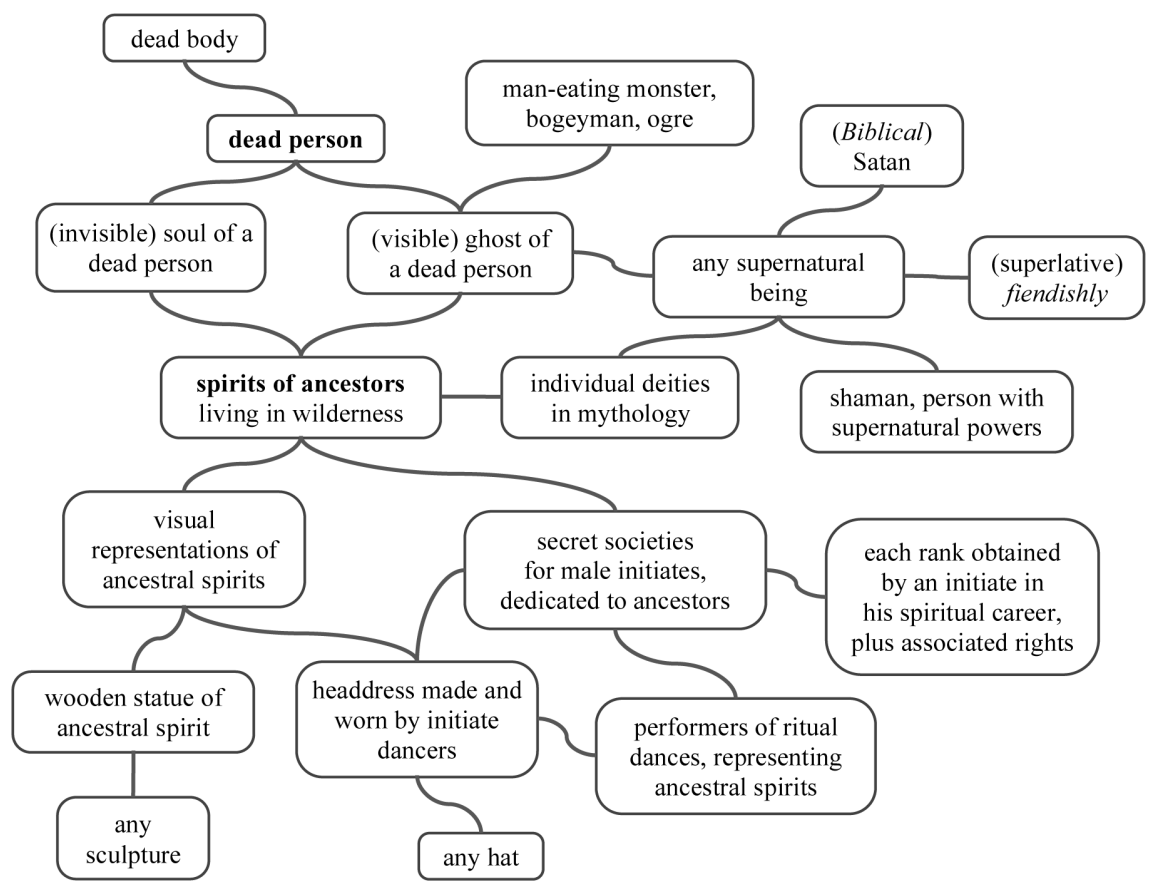

Figure 4: Lexical map showing the maximal polysemy associated with reflexes of *[a]tamate 'dead man, ghost, spirit+' 
Even though ${ }^{\star}[a]$ tamate can refer to a corpse, its most common reference is to the dead, as creatures endowed with some form of post mortem life. This is thus the term for 'ghost' - whether the phantom of a specific individual, or an unidentified spectre. The same word commonly designates any man-eating monster, ogre or bogeyman in stories told to children. Their nature of 'living dead' explains their hunger for fresh human flesh, whose presence they feel mostly through the sense of smell. These ghosts form a populace of nameless and indistinct spirits, who haunt the depths of the forest and of the night, always ready to harass the unsuspecting mortal. They haunt various places in the islands (\$4.5.2), which are feared and avoided for that reason.

By extension, *[a]tamate is sometimes the cover term for any supernatural being or spirit, whether it originates in a dead human or not. Even though it may refer to benevolent spirits - including the ${ }^{\star} \beta u i$, the higher deities of ancestral mythology (§4.4.4) - its frequent association with scary creatures may be the reason why *[a]tamate was equated, in the Christian religion, to Satan.

But the culturally most significant meaning of * $[a]$ tamate is when it refers collectively to the spirits of ancestors. These are normally thought of as benevolent towards mankind, as they take care of mortals and guide them through existence; as such, they are both feared and respected. This association 'ghost''ancestral spirit' is in turn the source of a cascade of metonymies that are central to customary representations. Initiation rituals, which have partly fallen into disuse today though they survive in some locations, entail that each male individual, during the course of his adult life, has to go through a number of steps in his spiritual career. Each step corresponds to a distinct circle or "secret society" (Codrington 1891: 69-92), and is associated with a specific guardian deity or 'ancestral spirit'; for example, on Motalava, the third rank of initiation was set under the aegis of Niwis, the 'Owl' spirit. The word *[a]tamate refers to that guardian deity, but also, by metonymy, to the 'secret society' set under its protection. In a way similar to what happens in other "status-alteration systems" also found in Vanuatu (Bolton 2003), each of these societies constitutes a distinct rank that comes with particular rights and obligations - all subsumed under the word $\star[$ a]tamate.

The activities performed by the initiates of each rank include learning about ancestors through myths, songs and visual representations of all sorts. They learn how to carve sculptures of specific spirits; in Mwotlap, the word *[a]tamate not only refers to these religious icons, but can even be extended to any figurative sculpture - in competition with ns-totyal we saw earlier (\$3.4). Finally, an essential embodiment of the ancestral spirits is in the form of adorned headdresses that will be worn by initiate dancers, as they perform ritual dances in public (Vienne 1996). Once again, the noun *[a]tamate will refer not only to the 
spirits themselves, but also to the dancers who embody them, as well as to their headdresses; by extension, the word can sometimes refer to any headdress, mask or hat (Codrington 1891: 80).

All these senses are represented in Figure 4. Languages differ as to the precise semantic extent of their reflex of *[a]tamate. Thus in Mota, the word tamate colexifies all these meanings; so does na-tmat in Mwotlap, except for the superlative use. In several languages though, this noun undergoes the competition of other words: thus the evil ghosts of stories are called alternatively timiat or œrœr in Vurës; Pama? or oror in Vera'a; ætmæt or tayrı (§4.8) in Lakon. In Mota, ritual headdresses are called either tamate or kokoa (François, pers. data). In the two Torres languages, tomet is restricted to positive uses (ancestral spirits; secret societies; ritual headdresses, also called $k^{w}$ วyar) - whereas evil spirits are called by other names - HIw $\eta^{w} e$, LTG $\eta^{w}$ ie or $\beta a \beta \partial r o$. These local innovations are probably more recent than the general polysemy of $\star[a]$ tamate represented in Figure 4.

The broad polysemy of *[a]tamate deserves a central place in any study of etymology in this group of islands. While the literal meaning *ata-mate 'dead person' leads naturally to 'ghost', it takes a longer semantic path to reach such senses as 'fiendishly', 'sorcerer', 'Satan' or 'hat'.

\subsubsection{Words and phrases based on *[a]tamate}

The noun *[a]tamate is a significant etymological source not only due to its internal polysemy, but also through the many compound words and phrases which are based on it. I will only mention here a selection.

When an edible fruit has a variety that is inedible for humans, the latter is sometimes called '[fruit] for ghosts'. Thus in Mwotlap, the sweet $n a-\gamma \beta r \gamma$ 'Malay apple, Syzygium malaccense' contrasts with the unedible variety na- $\gamma \beta$ r $\gamma$ yan tamat (lit. 'Malay-apple for ghosts') 'Syzygium jambos'.

The two hollows on the small of one's back are called *mata-i [a]tamate 'ghost's eyes':

(45) *mata-i [a]tamate 'ghost's eyes' $\rightarrow$ 'hollows in small of back': мTP na-mte-tmat; мTA mate-tamate

Not surprisingly, some compounds based on *[a]tamate are names of individual spirits from the mythology. Each one gives its name to the society of initiates who worship it, as well as to a ritual dance performed to celebrate it. Here are three examples: 
(46) *[a]tamate wasawasa 'smooth ghost' $\rightarrow$ 'name of a spirit':

мTP na-tmat wawah; MTA tamate wasawasa

(47) *[a]tamate memeyeli 'bow-legged ghost'

$\rightarrow$ 'name of a spirit; a manly dance':

мTР na-tmat-mumyIl; мTA tamat-memeyel

(48) *[a]tamate werewere 'whining ghost'

$\rightarrow$ 'name of a spirit, whose whining voice is heard in the dark and scares away the profane; name of the secret society that embodies this spirit' мTP na-tmat-wejwej; мТА tamate-werewere

When a young man is initiated to a secret society, he becomes *lesu [a]tamate 'entitled to ghosts' - that is, 'entitled to have symbolic access to the world of ancestral spirits':

(49) `lesu [a]tamate 'entitled to ghosts' $\rightarrow$ 'initiated, admitted to a society': LTG lih-tamet; LYP lis-tamat; MTP lis-tamat; LMG lis-Pama?; MTA les-tamate

Only they will be allowed to 'hold spirits', that is, create representations of these spirits in the form of sculptures, tattoos or headdresses:

(50) *tauri [a]tamate 'hold ghosts'

$\rightarrow$ 'create visual representations of spirits':

LHI ho $\backslash$ trj n-tamat; LYP tøøj n-tamat; vLw tij n-tamat; мTP trj na-tmat;

LMG Pør n-Pama?; DRG tur J tmat; KRO tur tamat; LKN (yih) ætmæt

The word *[a]tamate occasionally forms compounds referring to supernatural and other awe-inspiring forces of the world:

(51) *[a]tamate yaruyaru 'wading ghost' $\rightarrow$ 'tornado, waterspout'

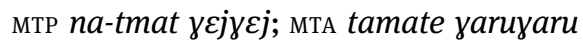

Similar phrases are used to name man-made items whose power or effect triggers the same sort of awe as ghosts or monsters:

(52) *[a]tamate $t^{m} b^{w} a$ 'shooting ghost'

$\rightarrow$ '(anc.) bamboo blowpipe; (mod.) gun, rifle':

мTP na-tmat tI $\widehat{k p}^{w}$; vRs timiat tı $\widehat{k p}^{w}$; мTA tamate tikp ${ }^{w} a$ 
(53) *[a]tamate wosa 'slapping ghost' $\rightarrow$ 'a membrane drum of northern Banks Islands, whose thick cover of leaves is punched to obtain a loud, deep sound'13

LYP n-tamat-wวs; мTP na-tmat-wวh; LMG Pama-wวs; vRs timiat-wos

(54) 'small ghost' $\rightarrow$ 'harmonica, radio, tape-recorder, loudspeaker' HIW wte tamet

A last phrase involving * [a]tamate is the name of the 'shaman' in the Torres islands, ${ }^{*}[a]$ tamate rono. It will be the object of a discussion in $§ 4.6$.

\subsubsection{The many kinds of spirits}

Even though reflexes of ${ }^{*}[a]$ tamate are everywhere the cover term for most supernatural beings, each local culture has its own names for different kinds of spirits, whether good or evil, minor or prestigious.

To take just a sample from the language Mwotlap, evil phantoms include Lisipsip 'a female creature with long hair, who hides in banyan roots and kidnaps children'; Napsisyon 'a scary female ghost with long breasts, who cries on the road at night and brings a curse to childbirth'; $N \varepsilon \overparen{\eta m}^{w} \varepsilon$ 'Seasnake, a succubus

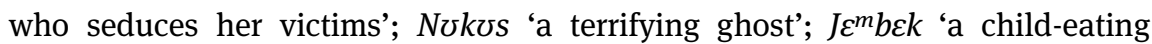
ghost', and so on. In addition, Mwotlap folklore mentions small imp-like creatures who live in the bush, and are not deemed harmful: some of them are called the Kakam jj ${ }^{14}$ 'elf-like creatures who live in the forest', others are $N^{n}{ }^{n} d^{m}{ }^{m} b i t$ 'fairylike creatures who make and give away shellmoney'; others again $\mathrm{Nat}^{m} \mathrm{bun}^{\mathrm{m}} \mathrm{bun}$ 'fairy'.

While other languages occasionally have spirits with similar names, it is more often the case that each community has developed its own idiosyncratic folklore. For example, Gaua people also have their elves (François forthc.), but they are called *Watayoriyori (>DRG Watyoryor, LKN WItayI'yI:), a word with no known etymology, and no relation with the names used in Mwotlap. It would be an interesting topic to compare the names and attributes of various creatures of the folklore in this region, and beyond.

13 See François and Stern (forthcoming).

14 Cf. the Kakamora creatures of Makira, in the Solomon Islands (Fox and Drew 1915; Fox 1962). 


\subsubsection{The primal deities}

Despite the variety of terms, one root stands out as a widespread and important word, besides ${ }^{\star}[a]$ tamate. This term is ${ }^{\star} \beta u i$, which may perhaps be glossed 'primal spirit' or 'deity':

(55a) ${ }^{\star} \beta u i \rightarrow$ 'primal spirit; deity':

HIW $w \ddot{t}$; LTG $w \ddot{t}$; LHI $n-\beta u$; LYP $n-\beta u$; vLW $n-\beta u$; MTP $n u-\beta u$; LMG $n-\beta u$; VRS $\beta \ddot{u}$; MSN $\beta u$; MTA $\beta u$; DRG $\beta u$; KRO $\beta u$; LKN $\beta u ;$; MRL $n u-\beta u$

Codrington (1891), and after him Ivens (1931), discuss the reference of Vui in the "religion of Mota"; their observations are mostly confirmed by what I heard from other languages, and can safely be assigned to the protoforms. On the one hand, *[a]tamate primarily refers to "ghosts", i.e. spirits emanating from dead mortals; they are mostly seen as dangerous creatures, who would be invoked, for example in malevolent sorcery. On the other hand, * $\beta u$ i designates the eternal spirits of the place, who were present even before mankind, and still inhabit the forest. These primal spirits created the world as demiurgic forces: they can legitimately be compared to deities or "gods" (see §4.4.6), whose prestige and aura rank much higher than *[a]tamate. Ghosts (*[a]tamate) are normally visible, and keep or take human shape to deceive their victims. By contrast, primal spirits ${ }^{\star} \beta u i$ are immortal and invisible, present in the very fabric of the land.

The etymology of ${ }^{\star} \beta u$ is unclear. Among the ones discussed by Ivens (1931), the most promising may be POc *puqun 'base (of tree); root, origin' - because these deities were present at the very beginning of Time. This tentative hypothesis is supported by the existence of similar metaphors in modern languages e.g. Koro l- $k p^{w}$ ItI $\beta \mho n \mho$ 'the Origin of the World', literally 'at the root of land' (François forthc.). It is possible that ${ }^{\star} \beta u i$ can further be analysed as a radical ${ }^{\star} \beta u$ ( $<{ }^{\star}$ puqun) followed by the suffix ${ }^{\star}-i$ (POc ${ }^{\star}$-qi) of inalienable nouns (see François 2005: 488); if so, the string ${ }^{\star} \beta u$ - $i$ could receive the literal gloss the Origin'. Due to the brevity of the forms involved, this particular hypothesis remains speculative.

The contrast between ${ }^{\star} \beta u i$ and ${ }^{\star}[a]$ tamate is sometimes preserved to this day. Banabas Womal, a knowledgeable man from Koro, explained to me their difference in essentially the same terms as those reported by Codrington. Hess (2009: 162) glosses Vurës / $\beta \ddot{\mathrm{u} /}$ as 'pure spiritual being, non-human', and contrasts it with other forms of spirits. But in some languages, the reflexes of ${ }^{\star} \beta u i$ and of ${ }^{\star}[$ a]tamate have become almost synonyms - at least according to some speakers. Thus in Lehali, even evil spirits can be referred to using ${ }^{\star} \beta u i-$ in the phrase $n$ - $\beta u$ sæt 'evil spirits' - a sense which is elsewhere restricted to 
*[a]tamate. In Löyöp, one can even speak of $\beta$ u tamat 'evil spirits', a phrase that includes reflexes of both roots. In two languages, the term ${ }^{\star} \beta u i$ has taken an abstract meaning, that refers to the evil force of certain creatures - including of ghosts:

(55b) $\quad \star \beta u i \rightarrow$ 'supernatural power of a ghost or spirit; evil force': LTG $w \mathcal{H}$; LMG $n-\beta u$

In this sense, ${ }^{\star} \beta u i$ is taking over a meaning which is normally expressed by other roots, such as *mana, *lalaßi, *tayaro (\$4.8).

In modern times, the same term ${ }^{\star} \beta u i$ is also used to translate the Christian

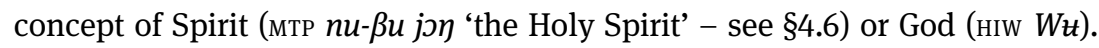

\subsubsection{The pantheon of northern Vanuatu}

Some * $\beta u i$ spirits are named, and constitute, as it were, the pantheon of northern Vanuatu mythologies.

The name of the main deity of the Banks Islands is known in the literature as "Qat", after its spelling in Mota orthography. His name reconstructs as ${ }^{\star m} B^{w}$ atu:

(56a) ${ }^{\star m} B^{w} a t u \rightarrow$ 'name of the principal cultural hero of the Banks Is, creator of the world and of institutions':

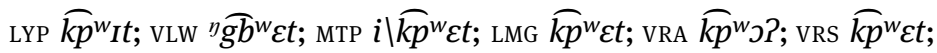
MSN $\widehat{k p}{ }^{w} \varepsilon t$; мTA $\widehat{k p^{w}} a t$; NUM $\widehat{k p^{w}}{ }^{w} a t$; DRG $\widehat{k p}^{w} a t$; LKN $\widehat{k p}^{w} a t$; MRL $k^{w} \varepsilon t$

The cycle of Qat is the most famous myth of the Banks Islands (Codrington 1891: 156; Vienne 1984; François forthc.). Qat is the deity who created the world; who brought the alternation of day and night; who sculpted the first woman; who designed some of the laws, as well as the language of songs. ${ }^{15}$ Ivens (1931: 159) proposes to link his name to the noun (21) ${ }^{\star m} b^{w} a t u$ 'head' - a link which is possible, though not entirely convincing.

One connection that is uncontroversial is the one made by Codrington (1891: 86-92) between the name of the hero "Qat" and the Qatu, the name of secret societies that were in use in the islands further South (Maewo, Ambae, Pentecost). Note in passing the usage of designating these secret societies with the name of

15 While Torres Islanders tell similar stories, they call the hero with another name: see below, under (60). 
a spirit or god: this is parallel to the designation, in the Banks islands, of these societies with the polysemous term *[a]tamate 'ancestral spirit' (§4.4.2). Even though the Banks languages never designate these societies with the name of their god ${ }^{\star m} B^{w} a t u$, they still draw a connection between his name and the secret world of young initiates. Indeed, the most prestigious dance of the Banks Islands - one in which male initiates, covered with headdresses, embody ancestral spirits (Codrington 1891: 85; François 2008a, François and Stern, forthc.) - is designated by names that also point to a protoform ${ }^{\star m} b^{w} a t u$ :

(56b) $\star^{m} b^{w} a t u \rightarrow$ 'a highly prestigious dance with a secret song, performed by initiates dressed as ancestral spirits':

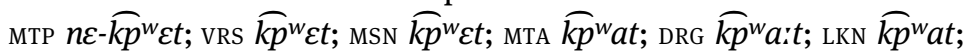
MRL $n \varepsilon-k^{w} \varepsilon t$

Qat is constantly bullied by his eleven brothers, who are all called *Tayaro:

*Tayaro $\rightarrow$ 'a mythological figure, elder brother of the hero Qat': vLW Tayaj; мTP Tayaj; LMG Tayar; vRs Tayar; MSN Tayar; MTA Tayaro

Among the brothers, two characters are called *Tayaro Lolomarani 'smart Tagaro' and `Tayaro Lolo ${ }^{m} b^{w}$ oni 'foolish Tagaro' - see (30)-(31) above. This name *Tayaro is reminiscent of a major Oceanic deity, found further south in Vanuatu - under the name Tagaro - and more famously in Polynesia - as Tangaroa (Marck 1996, Biggs 2006). I will come back to this connection in $\$ 4.8$ below, as I discuss a related term *tayaro 'supernatural force embodied in a spirit or a stone'.

The main enemy of Qat, known in Mota as Qasavara, reconstructs as $\star m B^{w}$ asaßara:

(58) ${ }^{\star m} B^{w}$ asaßara $\rightarrow$ 'a giant ogre, enemy of the hero Qat':

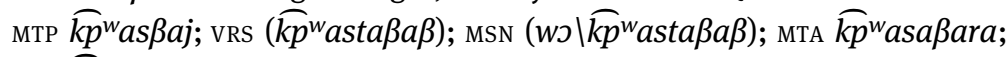

LKN $\overparen{k p}{ }^{w}$ as $\beta a l$

The first element of his name is ${ }^{\star m} b^{w} a s a$ 'bald head'; the second element varies, and is opaque.

Another of Qat's foes was evidently called ${ }^{\star}$ Dule. His name is proverbially associated with lie and deception:

(59a) ${ }^{\star n}$ Dule $\rightarrow$ 'name of a trickster spirit, who constantly deceives Qat': MTP $\left.i\right|^{n} d \mho l$; LMG $t \mho l$; VRS ${ }^{n} d \mho l$; MSN nøl; MTA nule 
Stories of ${ }^{\star n}$ Dule are plentiful on Vanua Lava (Hess 2009: 149, 219), but practically unknown elsewhere. Interestingly, knowledge of regular sound correspondences make it possible to propose a connection between the name of this deity and a word used in the Torres Islands to designate a magic stone:

(59b) ${ }^{\star n}$ dule $\rightarrow$ 'a standing stone endowed with supernatural powers, inhabited by a spirit; a stone statue representing such a spirit': HIW tuja; LTG tula

Torres islanders used to erect these magic stones at the entrance of their *yamali, the sacred houses of high chiefs (\$4.7.1). They still fear them nowadays. Another rival of Qat is *Marawa 'Spider':

(60) ${ }^{\star}$ marawa 'spider' $\rightarrow{ }^{\star}$ Marawa 'name of a spirit who first deceives Qat, but eventually becomes his ally': HIW ma ${ }^{g}$ Lawว; LTG marawว; LHI $n$-majaw; LYP n-majaw; vLW n-majaw; MTP na-mjaw; LMG n-mornw; VRA marawa; VRS maraw; MSN maraw; MTA marawa; DRG mraw; KRO maraw; OLR maraw; LKN maraw wImarawraw

This mythological figure is of secondary importance in northern Banks, and only present as a character in the myth of Qat. However, in the Torres Is, the main hero of myths - often equated with the Qat of the Banks Is - is called HIW m $^{g}{ }^{2}$ L $\beta$ tit; LTG marawəhih, two forms which may be related to *Marawa.

The name *marawa also appears to bear some significance on Gaua (François forthc.). Thus in Lakon, maraw designates a type of ritual headdress that is worn by initiated young men, along with the more noble ætmæt. Besides, all languages of Gaua (except Nume) designate their traditional myths and stories as literally 'Stories of Spider':

(61) `susur[ay]i mbula-i Marawa 'stories of Spider' $\rightarrow$ 'traditional story, myth': DRG susriy-mble-mraw; KRO ususrế ${ }^{m}{ }^{m}$ bele-maraw; OLR ususra:-pulI-maraw; LKN su'su:-pule-maraw

The phrases in (61) are reminiscent of the way in which three languages of Vanua Lava call their myths, literally 'the Voice of $\beta u i$ spirits':

(62) `alina-i $\beta u i$ 'voice of higher spirits' $\rightarrow$ 'traditional story, myth': VRA $n I l \eta \jmath-\beta u$; VRS $\varepsilon l \eta \varepsilon-\beta \ddot{u}$; MSN $\operatorname{l\eta } \varepsilon-\beta u$

A similar example is the way northern Vanuatu people designate the special speech register they use in sung poetry (François 2008a; François and Stern 
forthc.). This archaic language, perceived as an echo of primitive times and extinct voices of the past, is known in Mwotlap as na- $\beta a p$ non $i \widehat{k p}^{w} \varepsilon t$ 'the lan-

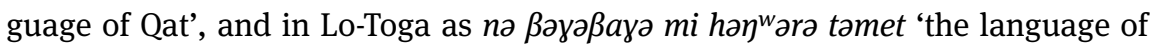
Ancestral Spirits'.

\subsection{The dwelling places of ancestors}

The abode of the dead receives many names in the languages of northern Vanuatu. This diversity reflects not only the tendency for lexical innovation (§2.3), but also the variety of locations that can be associated with ghosts and spirits. Essentially, one can think of four different places which may be considered the abode of the dead:

- the graveyard, on the side of the village

- various rocks and places in the bush, which are said to be haunted

- the Other World, or "Hades": a specific location where spirits dwell

- the ritual location where the societies of spirits gather

\subsubsection{The graveyard}

Several languages have a phrase 'enclosure of ghosts' to designate a cemetery or graveyard, on the side of the village. While the original term for 'enclosure' ( ${ }^{\star}$ ara $<$ POc ${ }^{\star} q a R a$ ) has been replaced in some languages, the second element always reflects ${ }^{\star}[$ a] tamate:

(63) *ara [a]tamate 'enclosure of ghosts' $\rightarrow$ 'graveyard':

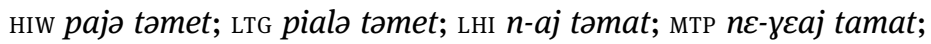
MTA yeara tamate

Due to the fear of the dead, the languages of southern Banks avoid the use of *[a]tamate here, and use a euphemistic phrase 'sleeping enclosure':

(64) 'enclosure for sleeping' $\rightarrow$ 'graveyard':

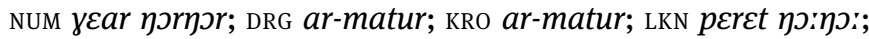
MRL $n \varepsilon-\gamma \varepsilon a r$ motur

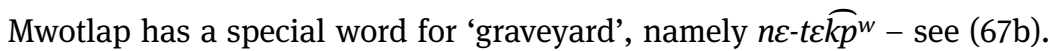

Finally, a noun whose meaning is related to this domain is ${ }^{\star m} b^{w} a r u$ 'grave'. When the form is a suffixable noun, I cite it here with a 3sg possessor *-na ('his/ her grave'): 
(65a) $\star^{\star m} b^{w}$ aru (-na) $\rightarrow$ 'grave (of s.o.), dug in the ground'

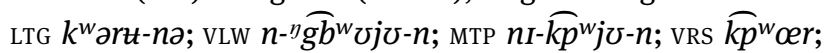

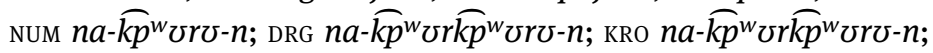
LKN $\overparen{k p}{ }^{w}$ arv-n

In the two Torres languages, the same etymon ${ }^{\star m} b^{w}$ aru has become the name of a special type of grave found only in these islands - namely, a large stone tomb or mausoleum which was erected only for highly ranked chiefs:

${ }^{\star m} b^{w} a r u \rightarrow$ 'stone tomb for highly ranked chiefs':

HIW $k^{w}{ }^{g}{ }_{L}$; LTG $k^{w} \partial r$

In the two Torres languages, the meaning 'grave in the ground' is not lexified by ${ }^{\star m} b^{w}$ aru any more: it has been replaced by a noun $\eta^{w} e t$, which originally designates the earth mounds created as one plants yams in the garden. Likewise, Mota calls the grave tawe tamate, literally 'a dead man's hill (mound)'.

The original meaning of the etymon ${ }^{*} b^{w}$ aru can be reconstructed as 'individual grave (of s.o.)'. However, in two languages, it has undergone semantic shift to refer to the whole area where graves are grouped together, namely 'graveyard':

$$
\begin{aligned}
& { }^{\star m} b^{w} \text { aru } \rightarrow \text { 'graveyard' } \\
& \text { VLW } n \varepsilon^{-} \widehat{ }^{\eta} g b^{w} \varepsilon j ; \text { MRL } n o-k^{w} G r
\end{aligned}
$$

We'll see below a final example of semantic shift affecting ${ }^{\star m} b^{w} a r u$ in the language Löyöp - see (68).

\subsubsection{Haunted places in the island}

Aside from the cemetery, another place where ghosts are to be found is in their various dwelling places across the islands - typically on rocky capes and promontories. These places receive various names; a common one is simply 'bad places' (e.g. LKN li ya sa), because these are locations where people fear to catch diseases or suffer from other misfortunes. Another simple name is 'place of ghosts' - e.g. vLw n-tons tamat.

Hiw and Lehali call these locations 'taboo places':

(66) 'taboo places' $\rightarrow$ 'places on the island haunted by ghosts': HIW nə $\eta^{w} u t \partial t \jmath k^{w}$; LHI $n \varepsilon-t p u$ 
These two phrases make use of an adjective 'taboo, sacred' which conveys both awe and fear. The word has reflexes with the same meaning in a few languages of the area:

(67a) ${ }^{\star} t a^{m} b u \rightarrow$ 'taboo, holy, sacred; worthy of awe and fear; off limits, unapproachable':

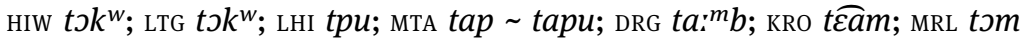

The word / $\mathrm{t} \mathrm{k}^{\mathrm{w}} /$ reflects a form with a labio-velar consonant ${ }^{\star} \operatorname{ta}^{\eta} \widehat{g b}^{w} u$, itself a regular reflex of ${ }^{\star} t a^{m} b^{w} u{ }^{16}$ The latter results from the rounding before $/ \mathrm{u} /$ of ${ }^{\star m} b$; but the unrounded variant was preserved in the other languages further south. The etymon to be reconstructed here is thus ultimately ${ }^{\star} t a^{m} b u$ 'sacred; forbidden' - that is, the very same word which, via Polynesian tapu, was borrowed into English as taboo.

Keesing (1985: 204) suggests that the best gloss for this common Oceanic word should be 'off limits'. He also points out the inherently relational nature of the term: "Something that is off limits, tapu, is always off limits to someone, not in and of itself; (...) being tapu, off limits, implies a context." This observation helps us understand the different meanings that are associated with this root ${ }^{\star} t a^{m} b u$ in our Torres-Banks languages. Thus Mwotlap has a noun $n \varepsilon-t \varepsilon \widehat{k p}{ }^{w}$ meaning 'cemetery', the regular reflex of ${ }^{\star} t a^{m} b^{w} u<{ }^{*} t a^{m} b u$ :

(67b) ${ }^{\star} t a^{m} b u \rightarrow[\mathrm{N}]$ 'cemetery, graveyard': мтР $n \varepsilon-t \varepsilon \widehat{k p}{ }^{w}$

A cemetery is "off limits" to humans, because it is the dwelling place of the dead *[a]tamate; it is an area which all villagers, in normal circumstances, will want to avoid.

In (66) and (67b), the focus was placed on a location associated with the dead (haunted rocks, cemetery), and the symbolic interdiction was directed at the living. Yet sometimes the perspective is reversed. Thus in Mwerlap, the noun ns-tom refers to a conventional sign made with certain leaves, that is put up at an entrance in order to deny access to undesirable guests [cf. (76)]; it is especially used to scare evil spirits away from a newborn baby (Marie Durand, p.c.):

16 Similar correspondences between a reconstructable ${ }^{\star m} b^{w}$ and a rounded velar $k^{w}$ in Torres languages, can be seen in (21); (65b); (76b); (80). The vowel is also regular, as shown in the rule in $\left(6^{\prime}\right)$. 
(67c) ${ }^{\star} t a^{m} b u \rightarrow[\mathrm{N}]$ 'a sign marking a place as taboo or forbidden, especially against ghosts’: MRL no-tom

In this particular case, the focus of ${ }^{\star} t a^{m} b u$ is on a location associated with the living (the house of a newborn baby), and the taboo sign is directed against the ghosts.

Finally, besides its adjective tap 'taboo', Mota has a noun tap that refers to a day of mourning ordered by a secret society (tamate), when no drumming, singing or playing are allowed (Codrington and Palmer 1896: 196). This obviously has the same origin:

(67d) ${ }^{\star} t a^{m} b u \rightarrow[\mathrm{N}]$ 'day of silence in sign of mourning': мтA tap

This sense too illustrates the strong connection that exists between the word ${ }^{\star} t a^{m} b u$ and the fear of death. The same root ${ }^{\star} t a^{m} b u$ will be mentioned again in (76), and in $\$ 4.6$.

Löyöp draws a connection between 'grave' or 'graveyard' on the one hand, and 'place haunted by spirits' on the other. It lexifies the latter meaning with a regular reflex of the root ${ }^{\star m} b^{w} a r u$, which we saw in (65a) above with the sense 'grave':

(68) ${ }^{\star} b^{w}$ aru 'grave' $\rightarrow$ 'area in island haunted by ghosts and spirits':

LYP $n \emptyset-\widehat{k p}{ }^{w} \emptyset j$

Ancestral spirits are known for their love of dancing: many stories portray them as a group of merry ghosts who spend their nights in frenetic dances, somewhere in the bush. It is therefore not an accident that the noun ${ }^{\star}$ sara, which normally designates the open space in the midst of villages where dances are performed (Clark 2009: 238; François 2011a: 183), sometimes designates the dancing place of ghosts in the wilderness. This is done through a phrase which can be reconstructed as *sara-i [a]tamate:

${ }^{\star}$ sara-i [a]tamate 'dancing-place of ghosts'

$\rightarrow$ 'the abode of ancestral spirits, in the wilderness':

LYP li sIjI-tmat; MTP le-hje-tmat; LMG scre-Pama?; VRA scre-?ama?;

VRS scre-timiat

This word has given its name to the highest volcano on Vanua Lava island, shown on maps as Suretimeat or Sere'ama. It is considered by the islanders to be the meeting place of spirits for their dances (Hess 2009: 166). 


\subsubsection{The abode of the dead}

Most of the words we have seen in §4.5.2 are common nouns: they can refer to more than one place in the same island. By contrast, it is not rare to hear the idea that ghosts and spirits, even though they occasionally inhabit various places in the wilderness, really belong to one specific place where they dwell for eternity - what we call Hell, the Underworld or Hades. Interestingly enough, the representations of Hell have been little influenced by the otherwise widespread Christian religion. Far from coinciding with dual representations of "Paradise" or "Hell", the terms I was able to collect for the Underworld - either through interviews or through myths and stories - all reflect an ancient system of representations that remains vibrant today. They are also consistent with other accounts by previous observers (Codrington 1891; Vienne 1984).

A first cognate set involves a root *sura (or rather, as we'll see below, *asura), preceded by a prefix of unclear origin:

(70a) ${ }^{\star}[a]$ sura $\rightarrow$ 'abode of the dead, Hell':

LYP $w \mho \backslash s \mho j ;$ MTP $w \mho \backslash s \mho j ;$ LMG wIrI $\mid s \mho r ;$ VRS wIrI $\mid s \mho r$

The people of Gaua use the same term for the abode of the dead, but interestingly, they are very specific as to its location. Their myths explicitly locate the Other World under their majestic Gharet volcano (François forthc.):

(70b) ${ }^{\star}[a]$ sura $\rightarrow$ 'abode of the dead, located under a volcano':

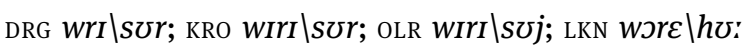

Thus, a Dorig myth explains how Wrisris, the god of Death and guardian of the Underworld, has his dwelling under the volcano of Gaua.

Interestingly, the Lakon word ahv: 'volcano' (in which the long vowel reflects ${ }^{\star} \mathrm{r}$, and $/ \mathrm{h} /{ }^{\star}{ }^{\star} \mathrm{s}$ ) is cognate with these sets. The tendency of Lakon to preserve pretonic vowels (François 2005: 470) requires the reconstruction of an initial vowel *a to the etymon, hence ${ }^{\star}$ asura:

(70c) *asura $\rightarrow$ 'volcano’: LKN ahซ:

This Lakon name for 'volcano' seems to be a local innovation; it is distinct from the other root which can be reconstructed for this meaning, namely * $\beta$ uro:

(71) ^ $\beta$ uro 'volcano' $\rightarrow$ 'volcano':

LHI $n$ - $\beta$ Jj; LYP $n$ - $\beta \mho j$; vLW $n \mho-\beta \mho j$; MTP $n \mho-\beta \mho j ;$ LMG $n$ - $\beta \mho r ;$ vRS $\beta \mho r ;$ MSN $\beta \mho r$; MTA $\beta r o$; NUM wa $w$ ur; DRG $v r$; OLR $n \backslash v j$ 
In other words, the original word for 'volcano', in the northern Vanuatu area, is ${ }^{\star} \beta$ uro, which bears no lexical relationship with the world of the dead. As for *asura, the origin of Lakon ahw:, it must have had a more specific meaning. Codrington and Palmer (1896) has a cognate form in Mota, with an interesting gloss:

(70d) $\star[a]$ sura $\rightarrow$ 'narrow entrance; esp. entrance into Hades': мTA sura

Likewise, regular correspondences make it clear that the following forms in the two Torres languages - despite their profane meaning - stem from the same word:

(70e) $\star \star[a]$ sura $\rightarrow$ 'deep and narrow cave’: HIw su' ${ }^{g}$ Lə; LTG hurə

All these forms suggest to reconstruct a word * $[a]$ sura, defined as 'deep and narrow opening inside a mountain or volcano, leading to the Underworld'.

But if the original meaning of $*[a]$ sura was only 'narrow entrance towards the Underworld', then what was the name of that Underworld? In fact, these northern Vanuatu languages have a second term to designate the abode of the dead, ^mbanoi:

${ }^{\star m}$ banoi $\rightarrow$ 'Hades, the abode of the dead': HIW pene; LTG pənə; LHI pInI; LYP $p ø n \varnothing ;$ VLW $a \mid m n \mho ;$ MTP $a \mid m n \mho ;$ VRS ${ }^{m} b ø n \varnothing ;$ MTA panoi; LKN panI

Hess (2009: 166) reports on interviews she had with a speaker of Vurës. On the one hand, he interpreted Wirisør (70a) as a "place of sorrow and sadness where souls receive their punishment for their immoral and evil practices", and compared it to the Christian "Hell". On the other hand, $\widehat{k p}^{w}$ aray ${ }^{m}$ bønø (in which $\widehat{k p}^{w}$ aran means 'cave') was equated with "Paradise", and described as a place of "joy and happiness". I have heard nowhere else of such a dichotomy between two realms for the dead that so closely reflects syncretism with Christian beliefs.

Interestingly, this Vanua Lava islander located Paradise under the volcano of the neighbouring island of Gaua. In doing so, he did not link the volcano to the etymon *asura (as in Wirisør), but to the other etymon ${ }^{\star m}$ banoi ( $>$ mbønø). But why? No language of the Torres-Banks area seems to associate ${ }^{\star m}$ banoi specifically with volcanoes. In fact, this connection is found in other languages of Vanuatu further south (Clark 2009: 80):

$$
\begin{aligned}
& \star{ }^{\star m} \text { banoi } \rightarrow \text { 'volcano': Paama vanei; Namakir mbane; Nguna na-panoi } \\
& \star{ }^{\star m} \text { banoi } \rightarrow \text { 'volcanic ash': Tamambo mbanoi; Uripiv mbenu; Lewo pani }
\end{aligned}
$$


Clearly, ancient cultures of Vanuatu have long associated the abode of the dead with volcanoes. Should one observe these words on a synchronic basis in each language taken separately, this connection would appear nowhere; it only comes to light thanks to language comparison. In sum, I propose to reconstruct the two following meanings for these two words:

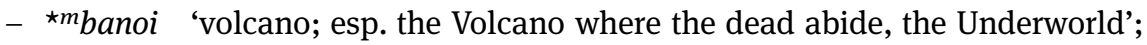

- *asura 'a long and narrow cavity in a mountain or volcano; esp. the long and narrow corridor leading to the Underworld ( ${ }^{\star m}$ banoi)'

Nowadays, the association of ${ }^{\star m}$ banoi with volcanoes has been mostly lost. In Hiw, the word Pene! has become a respectful salute when parting with someone: one says '[See you in] the Other World!' to make sure that, should anything bad happen to one's friend, their soul will safely reach the abode of the dead, rather than wander around the world like a lost soul.

Modern reflexes of ${ }^{\star m}$ banoi refer to an abstract location - Hell - which most modern speakers view as a remote place, often with no further specification. Except for Gaua island where the Gharet volcano is still a major landmark, elsewhere the abode of the dead is seldom identified in the actual geography of the islands; it is usually described as a 'very remote' place - to the point that its name is sometimes used, jokingly, to mean 'somewhere very far'. Some speakers of Mwotlap told me that Amnv may be somewhere in the ocean - in conformity with the traditional link, heard in some stories, between ghosts and the sea.

The most reliable information I collected was in an interview with Sesil Pilageliqe, a highly knowledgeable shaman (\$4.6) of Toga island who is still active, and has travelled oftentimes to the Other World. According to him, Pana ( $<{ }^{\star m}$ banoi) is located everywhere in the island, and nowhere in particular: ghosts and ancestral spirits inhabit the same world as ours, yet are invisible. The power of shamans and seers like himself precisely consists in being able to see the phantoms around us, and interact with them. After their mystical journey, they come back to our world, and become one of us again.

By contrast with ${ }^{\star m}$ banoi, the World of the Living is called *marama:

(73) ${ }^{\star}$ marama $\rightarrow$ 'world; especially the World of the Living':

HIW ma ${ }^{g}$ Lamə; LTG maremə; LHI $n$-majam; LYP $n$-majam; vLW n-majam;

MTP na-mjam; LMG n-morom; VRA marama; VRS maram; MSN maram;

MTA marama; NUM maram; DRG mram; KRO maram; OLR maram;

LKN maram; MRL na-maram

The noun *marama is etymologically linked with the notion of light: whether as daylight, as moonlight ( $\rightarrow$ marama 'moon' in various Oceanic languages: Ross, 
Pawley, and Osmond 2003: 159) or as metaphorical light ( $\rightarrow$ maPama 'intelligence' in Marquesan: Charpentier and François forthc.; mārama 'understand' in Māori: Pawley, p.c.). ${ }^{17}$ This contrasts with the typical association of the dead with darkness - either the one that reigns in the Underworld, or the darkness of Night, when ghosts come out to dance.

\subsubsection{The secret societies}

Finally, the last places where the dead can be said to dwell are the secret locations where they are symbolically revived by initiate societies. As an institution, these societies or clubs are usually called *[a]tamate, using the same name, metonymically, as the ancestral spirits themselves - see Figure 4 in §4.4.2. However, other words are also connected to that lexical domain.

One central term refers to the secret meeting place of male initiates: * salayoro (Codrington 1891: 69-86; Vienne 1984: 319).

(74a) ${ }^{\star}$ salayoro $\rightarrow$ 'sacred enclosure in the bush where initiation rituals are carried out, and where spirit dances are prepared':

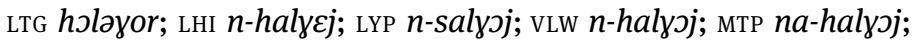
LMG $n$-sblyœr; VRA salyor; VRS salyor; MSN salyor; MTA salayoro; NUM salıwor; DRG salyor; KRO salyor; OLR salwJj; LKN salwo:

The ${ }^{\star}$ salayoro takes the form of a temporary shelter erected somewhere in the bush, at a distance from the village. It will be used only for a few weeks, during a cycle of initiation rituals; then it will be destroyed or abandoned until the next cycle, which may not take place for another few years, usually triggered by the preparation of a dance ceremony or festival. This enclosure is devoted to the education of young male initiates (49), who are to live in the bush during several weeks, away from the profane village. This is where they will have to endure physical ordeals, but also learn from their elders some secrets on a variety of subjects - on the meaning of rites and symbols, on the cosmogony and the mythology, on the ritual arts of singing, dancing or representing ancestral spirits (50), etc. These mysteries are to be kept away from the profane women, children, foreigners. And indeed, some languages use the same word *salayoro to mean 'secret, mystery':

17 For northern Vanuatu examples of the semantic link between 'light' and 'intelligence', see $\S 4.2$. 
(74b)

*salayoro $\rightarrow$ 'secret, mystery; taboo subject':

VLW $n$-halyə; MTP na-halyj; vRS salyvr

The precise etymology of *salayoro is not entirely clear. It is most probably a compound *sala-yoro, where *sala may be the noun 'road, path, way' $(<\mathrm{POc}$ ${ }^{\star}$ jalan). As for ${ }^{\star} y o r o$, it is reminiscent of an adverb * ${ }^{\star}$ oro with a highly polysemous meaning:

(75) *yoro $\rightarrow$ '[do s.th.] so as to surround, cover, obstruct, prevent, protect...':

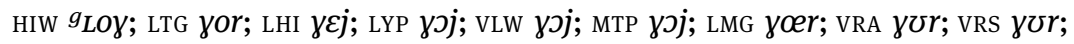

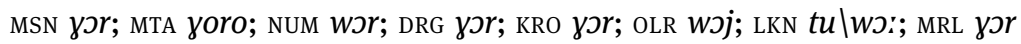

While the principal use of *yoro is as an adverb or verb modifier (cf. François $2000 b$ ), the word is more rarely found as an adjective, meaning 'closed' (cf. sense 'obstruct') or 'taboo, secret' (cf. sense 'prevent'). If indeed *sala is the noun 'path', then my interpretation of *salayoro would therefore be 'secret path'.

It is not an accident that some languages designate the same secret enclosure precisely using the root ${ }^{\star} t a^{m} b u$ 'taboo, holy'. We saw in (67) above that this word was often associated with the dead, via such meanings as 'graveyard', 'mourning', or 'place haunted by ghosts'. This radical ${ }^{\star} t a^{m} b u$ was the source of a derived verb ${ }^{\star} t a^{m} b u-a$, 'render (s.th.) taboo'. In some Banks languages, it is still used as a transitive verb:

(76a) `tam $b u$ - $a$ 'render (s.th.) taboo' $\rightarrow$ 'forbid access to one’s private territory (garden, house...), by standing up a conventional sign designed for that function':

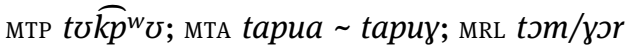

In the two Torres languages, the same form has become a noun referring to the secret enclosure which non-initiates must avoid:

(76b) * ${ }^{m} a^{m} b u-a$ 'render (s.th.) taboo'

$\rightarrow[\mathrm{N}]$ 'sacred enclosure in the bush where initiation rituals are carried out, and where spirit dances are prepared': HIw $t \theta k^{w} \theta$; LTG $t \partial k^{w} \partial$

In Hiw, the enclosure is sometimes named just $t \theta k^{w} \theta$, and sometimes $t \theta k^{w} \theta t \jmath k^{w}-$ literally 'a sacred-enclosure that is taboo' - a phrase in which the etymon ${ }^{\star} t a^{m} b u$ appears twice. In addition, Hiw has a phrase $\beta e n t \partial k^{w} t \jmath k^{w}$ (literally 'to go taboo'), a cover term for the various restrictions - mostly related to food or body - undergone by boys during their initiation. 
A whole set of lexemes can be found related to these initiation rituals: nouns referring to the fence of the enclosure, to symbolic divisions within it, to symbols used during initiation, to the various steps and tests taken by the candidates, and so on. However, for reasons of length, I shall refrain from discussing these.

\subsection{The shaman and the sacred}

A culturally important concept in the Torres languages is *[a]tamate royo, which refers to a healer or shaman:

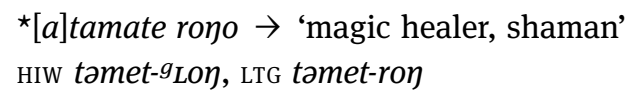

This is the name given to a healer with shamanic powers - someone who knows how to circulate across worlds, and access the hidden universe of ancestral spirits (cf. §4.3.2 above). Shamans are seers: they can see what is invisible to us, ordinary mortals. This skill gives them the ability, for example, to meet the soul of a recently dead person, enquire about the cause of their death, and bring back the answer to the mourning relatives. But the shaman's main role is to be a healer. When somebody is sick, this means their soul has been kidnapped by spirits ( ${ }^{\star}\left[\right.$ a]tamate), and carried away to the Other World ( ${ }^{\star m}$ banoi). Only a shaman has the power - aided by magic leaves - to migrate to that world, retrieve the lost soul of the person, and lead it back to the world of the Living. Many tales tell the story of how an old sorceress was thus able to retrieve the spirit of a dead hero and bring him back to life.

The etymology of * [a]tamate rono is tricky. The first element *[a]tamate must not be taken here in its sense 'ghost' or 'ancestral spirit', and instead takes on a rarer meaning 'supernatural being', i.e. 'person endowed with magical powers' (see Figure 4 in \$4.4.2). Besides, the second element *royo is also ambiguous. When questioned about the words in (77), modern speakers interpret them as 'spirit who listens'. This is due to the fact that the two languages have a verb 'hear, listen, feel' (HIw ${ }_{\text {LOV }}$, LTG ron) that comes indeed from a root *royo (POc ${ }^{\star}$ royoR). If this is correct, then ${ }^{\star}[a]$ tamate royo (lit. 'ghost hear') would mean literally 'a supernatural being who listens' - that is, a 'shaman'.

However, I would suggest that this modern interpretation is a case of folk etymology. An alternative hypothesis would be to understand *[a]tamate rono as meaning 'a supernatural being ( ${ }^{\star}\left[\right.$ a]tamate) that is sacred ( ${ }^{\star}$ royo)'. Indeed, besides the verb 'hear', a homophonous etymon *royo also reconstructs with a 
meaning 'sacred, holy'. It has been lost in the Torres - and is therefore inaccessible to modern speakers - but preserved in some of the neighbouring Banks languages:

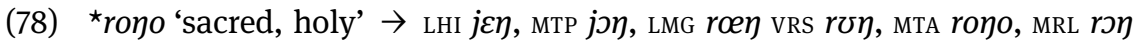

It seems that this word *royo may in turn be semantically related with *roroyo 'quiet, silent':

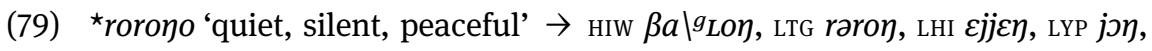

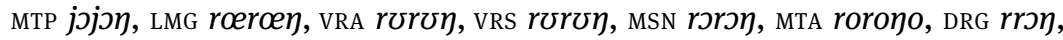

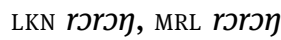

The sort of holiness evoked by (78) *royo is indeed one endowed with a peaceful aura of solemnity. It refers to the inherent sanctity of a person, a place or an object. While *royo entails a sentiment of awe and respect, it doesn't have the negative connotation of the word we saw earlier for 'sacred', namely (67) * $t a^{m} b u$ 'taboo, holy, sacred; worthy of awe and fear; off limits, unapproachable'.

Mota is one of the few languages which has preserved reflexes of both etyma, in the form of royo and tapu. Codrington and Palmer (1896) draw an explicit contrast between royo 'sacred, unapproachable, with inherent sanctity, not tapu' and tapu 'taboo, unapproachable, not to be touched, under a prohibition with the sanction of some mana belonging to men; so distinct from royo' (cf. Codrington 1891: 77, 181, 215). The opposition between the two types of sanctity is remarkably parallel to the contrast drawn by Benveniste (1969: 179) between two concepts of sanctity found in ancient Indo-European languages: respectively a "positive" notion - "that which is endowed with a divine presence" (Lat. sacer) - and a "negative" one - "that which is forbidden" (Lat. sanctus). The two concepts of Proto Torres-Banks seem to define a similar dichotomy that between a positive and inherent holiness of spiritual beings ( ${ }^{\star}$ rono), and the negative kind of sanctity that is sanctioned by society $\left({ }^{\star} t a^{m} b u\right)$.

The word *rono has received a Christian meaning in certain languages

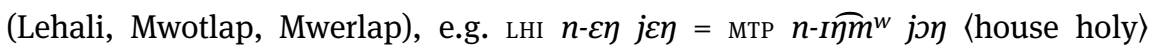

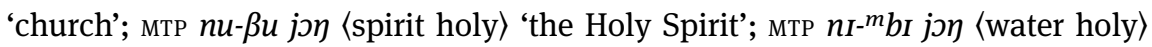
'holy water'; мтр $\beta a s u w$-jon 〈bathe holy〉 'baptize'. However, even today one can still hear phrases in which the character of holiness is linked to pre-Christian beliefs: thus a stone will be 'holy' (мтр $n \varepsilon-\beta \varepsilon t$ jगy) if it is haunted by the spirits of the land (nu- $\beta u$, cf. §4.4.5) - cf. Codrington (1891: 181). 
In sum, a plausible interpretation of the shaman's name (77) in the Torres Islands would be 'a supernatural being (*[a]tamate) that is sacred (*royo)', i.e. endowed with spiritual powers ( ${ }^{\star}$ mana, cf. §4.8.1).

\subsection{Power, wealth and aura}

\subsubsection{The system of chiefly grades}

The societies where initiates are taught the secrets of ancestral spirits have a public, open counterpart - namely, a system of hierarchical ranks in which powerful men accessed various levels of political prestige, by going through a number of ceremonies along their lives. The rank system - which mostly disappeared from the region during the 20th century - is described in the literature (Codrington 1891; Vienne 1972, 1984) as "suqe”, after its name in the orthography of Mota. From the linguist's perspective, the word's etymon reconstructs in Proto Torres-Banks as ${ }^{\star} s u^{m} b^{w} e$ :

(80) ${ }^{\star} s u^{m} b^{w} e \rightarrow$ 'political system based on a hierarchy of ranks, which individual men achieved through display of riches':

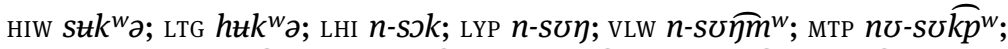

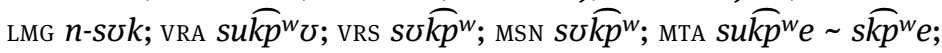
DRG $\beta \backslash s \mho k$; KRO $\beta \mho \backslash s \mho k$; LKN $\beta a \backslash s \mho k$

Reflexes of ${ }^{\star} s u^{m} b^{w} e$ are used as a noun but also as a verb, meaning 'take the steps to enhance one's grade in the rank system'. This term does not appear to be a compound, and has no clear etymology. However, it is useful to note that Vanuatu languages further south, which had a different political system, have words that are cognate with ${ }^{\star} s u^{m} b^{w} e$ : e.g. Araki supe 'supreme chief, high dignitary; the Christian God' (François 2002: 302); Nguna na-supwe 'idol, image of ancestor, god' (Clark 2009: 183).

The chiefly members of a ${ }^{\star} s u^{m} b^{w} e$ would meet in a special house reserved for them, the ${ }^{\star}$ yamali ( $<\mathrm{POc}{ }^{\star} k$ kamaliR 'men's house'). The ${ }^{\star}$ yamali was a house where highly ranked men would - among other activities - consume kava, ${ }^{18}$ a prestigious beverage made from a plant (Piper methysticum), which was often associated with magic practices. With the Christianisation and the disappearance of ${ }^{\star} s u^{m} b^{w} e$ practices during the 20th century, both the beverage and the men's

18 In this part of Vanuatu, the etymon for kava apparently reconstructs as *yaya (François 2005: 478), and ultimately originates in a POc etymon *kawaR 'root' (Lynch 2002). 
house have largely lost their sacred aura: they have become part of the profane daily life of modern islanders.

The way for a man to climb the political scale of ${ }^{\star} s u^{m} b^{w} e$ involved the public display of considerable wealth. This would take the form, typically, of a number of pigs $\left({ }^{\star m} b^{w} o e\right)$ that were killed by being struck ( $\left.{ }^{\star} \beta u s i\right)$ on the head with a wooden club ( ${ }^{\star m} b^{w}$ oroni). Besides, the candidate had to bring offerings of kava, along with massive quantities of shellmoney ( ${ }^{\star}$ somu). This shellmoney consisted of small cone shells (Conus sp.) that had been patiently filed into circular discs, then pierced and threaded onto a very long string of beads:

*somu 'Conus shell'

$\rightarrow$ 'traditional shell money, made of cone shells; (hence) modern money': LHI $n$-SIm; LYP $n$-Søm; VLW $n$-SIm; MTP nI-SIm; LMG $n$-søm; VRS søm; MSN sひm;

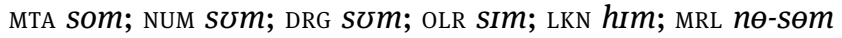

The quantity of such money required for some higher ranks could measure up to 10 fathoms in length, and involved considerable work on part of the candidate's female relatives. This shellmoney has now disappeared from most places, and only exists vestigially in some families; however, it is still in currency in Merelava (Marie Durand, p.c.) shellmoney used to be a marker of one's wealth. The equivalent of Eng. 'rich' is a phrase which can be reconstructed as ${ }^{\star} m^{w} e r a-i$ somu, literally 'child of shellmoney' [cf. (17)]:

${ }^{\star} m^{w}$ era-i somu 'child of shellmoney' $\rightarrow$ 'rich, wealthy':

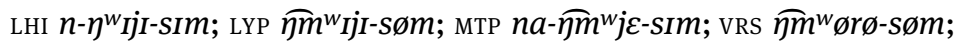

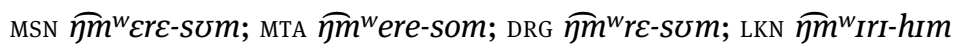

\subsubsection{The aura of high chiefs}

While the detail differed from island to island, the usual number of political ranks on the scale was between 12 and 14. Each rank had its own attributes (Vienne 1984), and its own name. I will only cite three of them here:

(83) * $l a^{n} d o \rightarrow$ 'name of a chiefly rank, relatively high':

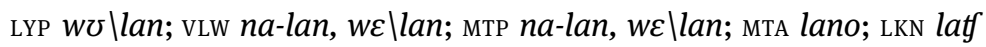

(84) *wo mata-i aloa (lit. 'the eye of the sun') 'rising sun, Orient' $\rightarrow$ 'name of a chiefly rank, among the highest':

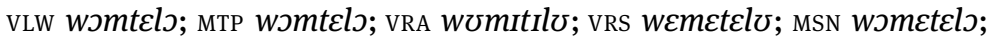

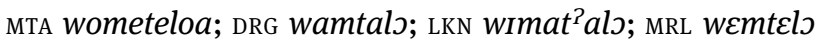


(85) *tayuru-i maliyo 'behind the clouds'

$\rightarrow$ 'name of a chiefly rank, among the highest':

LTG (kile tuka); VRS tewrü malıy; MTA we taur o maliyo; DRG tawri mlry;

LKN tawu: malry; MRL towur melry

The etymologies of the last two sets show how the prestige of high chiefs tends to be expressed with celestial metaphors: 'Rising Sun', 'Beyond the Clouds'. I also include here the Lo-Toga form kile tuka, even though it is not cognate with the rest, because the name of this high rank uses a similar metaphor: 'beyond the firmament'.

A man having reached one of the higher ranks would have gained considerable social prestige. He would then be called ${ }^{\star}$ taßusimwele:

${ }^{\star}$ taßusimwele $\rightarrow$ 'man of great rank, high chief':

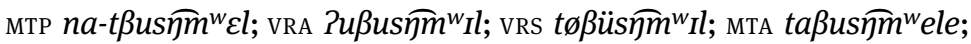
LKN taßusभुm ${ }^{w} \varepsilon l$

The word's etymology is tricky. In principle, it parses as ${ }^{\star}$ ta- $\beta$ usi- $m^{w} e l e$, literally 'one who has struck a Cycas palm'. However, the element ${ }^{\star} m^{w} e l e$ - while originally the name of the highly prestigious palm - does not designate here the plant itself, but stands for the high rank of the same name (87):

(87) ` $m^{w}$ ele 'Cycas palm' $\rightarrow$ 'name of a chiefly rank, relatively high':

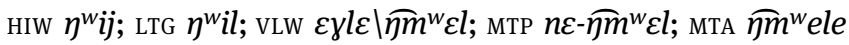

The underlying object of ${ }^{\star} \beta u s i$ 'strike, hit' is not ${ }^{\star} m^{w} e l e$, but an implicit 'pig', whose sacrifice is necessary to attain higher ranks. Thus the etymology of *taßusimwele is really 'a man who has killed [pigs] for the Cycas chiefly rank' (Codrington 1891: 55, 1896: 211) - hence 'a man of great rank'.

While the chiefly positions were restricted to men, some women also were regarded highly - either because they were the wives of high chiefs, or because they had gone through their own hierarchy of grades (Hess 2009: 10). The term then used is a reflex of ${ }^{\star} m^{w}$ otari:

${ }^{\star} m^{w}$ otari 'woman of high prestige'

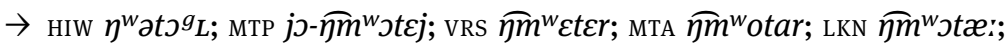
MRL $n \varepsilon-\eta^{w} \varepsilon t \varepsilon r$

The sons and nephews of a highly-ranked chief would also have prestige. It is possible to reconstruct a protoform * woyutu with this meaning: 
(89)

^woyutu 'young man of high prestige; admirable man'

$\rightarrow$ HIW wowut; MTP nø-wซyit; VRS wøwut; MTA wowut; KRO wuwut; LKN wuwut

Some of my consultants would liken this word with the western notion of 'Prince'. In Hiw, the two words $\eta^{w} \partial t{ }^{g}{ }_{L}$ and wowut have now taken on a profane meaning, that of an admirable woman and admirable man, respectively.

\subsection{Supernatural powers}

\subsection{1 *mana 'supernatural power'}

The social aura which surrounds high chiefs in the ancient political system, but also shamans and sorcerers, is inseparable from a notion of supernatural power, called *mana:

(90) ${ }^{\star}$ mana $\rightarrow[\mathrm{N}]$ 'supernatural power held by a person or a thing; magic force':

HIW manə; LTG menə; LHI $n$-man; LYP $n$-man; vLW n-man; MTP na-man;

LMG $n$-mon; VRA mana; VRS man; MSN man; MTA mana; NUM man; LKN man;

MRL na-man

This term mana (<POc ${ }^{\star}$ manay), widespread in the Pacific, has been widely studied by anthropologists working in that part of the world (Codrington 1891; Ivens 1931; Keesing 1984; Mondragón 2004). In various Oceanic languages, mana is a verb meaning 'be efficacious, be true, be potent' (Keesing 1985: 203); yet in northern Vanuatu, the use of mana as a verb is marginal: it is only found in a few languages (Mwotlap, Vurës, Mota), typically in phrases restricted to seafood, meaning '[fish, food] be poisonous'. In the Torres-Banks area, the principal use of *mana is as a noun, referring to a magical force that is present in certain places, objects, or individuals. A healer, sorcerer, magician either "has" or "lacks" *mana: e.g. in Mwotlap na-man aI mi kI (literally "there is some mana with him', i.e. 'he has mana'). A sacred stone, a haunted place, a valued name may also bear their own mana.

In itself, the power of *mana is amoral, and can be put to benevolent or malevolent use. Thus, a good poet is supposed to have *mana, a force that gives him his talent and inspiration; this *mana is transmitted from master to disciple, during a special ritual involving magic leaves. A high chief in the ${ }^{\star} s u^{m} b^{w} e$ would also have been endowed with considerable *mana, as he found the power to pursue his political career (Vienne 1984: 377); the term is not used when referring to the modern, secular forms of chiefdom. 
But the word ${ }^{\star}$ mana is also often associated with the awe and fear evoked by sorcery. Most languages use ${ }^{\star}$ mana to refer to the dangerous, supernatural power of ancestral and evil spirits. In Lo-Toga, menə hia (lit. 'evil mana') designates the practice of sorcery itself. Mwotlap has a derived verb manhey '[sorcerer] cast a spell on s.o.'.

\subsection{2 *lalaßi 'harmful aura of evil spirits'}

The languages of the area have other words to refer to the more or less magic power associated with a person or thing. One of them is *lalaßi:

(91a) *lalaßi $\rightarrow$ 'harmful aura emanating from an evil spirit': LMG $n$-lvl $\beta i$; DRG lal $\beta i$; KRO lal $\beta i$; LKN lal $\beta i$

I have mostly found this word in relation to evil spirits *[a]tamate, in a phrase like LMG $n$-lolßi Pama? 'the evil power of phantoms' - a meaning which other languages would express with *mana. The word *lalaßi has an interesting etymology, which can be reconstructed thanks to the conservative language Mota (Codrington and Palmer 1896: 43):

(91b) мта lala $\beta i_{-} \rightarrow$ 'the blast of heat; the blast of a swift passing body, as a falling rock'

This noun is itself derived from a verb lala $\beta$ 'send out a blast, burn, scorch', in turn linked to lala:

(91c) *lala $\rightarrow$ '[fire] burn clear and hot; smoulder': HIW jaj; LYP lal; vLW lal; MTP lal; LMG lol; мTA lala

In sum, the word ${ }^{\star}$ lala $i$ likens the harmful power of evil spirits to the scorching heat of a burning fire.

\subsection{3 *tayaro 'supernatural force embodied in spirit and stones'}

Finally, another word sometimes used to refer to someone's magical power is *tayaro (forms are here given with a 3sg possessor: 'his/her/its power'):

(92a) *tayaro (-na) $\rightarrow$ 'supernatural power emanating from a person, a spirit or a force':

LMG $n$-PbyrJ- $n \sim n$-Payar; VRs tayrJ- $n$ 
The semantics of this word family is puzzling, and deserves to be explored. Thus in Lemerig, the term Payar was defined as a supernatural power found with nonhuman spirits, or with "superior men" such as initiate men and high chiefs. By contrast, a Vurës speaker, faced with this Lemerig definition, explained that the term tayrs- $n$ in Vurës could only refer to the magic force of a person (sorcerer, healer), but not of a spirit.

Other reflexes of *tayaro do not even have any connection with the notion of magic power. For example, Vurës has an etymological doublet tayar '(good or bad) outcome of s.o.'s behaviour, (good or bad) luck', which is restricted to human, non-magic referents. Likewise, Mwotlap has a reflex na-tyaj 'fatigue, exhaustion', perhaps via a meaning 'effect of s.o.'s actions'.

So, if there was a semantic shift, was it from the sacred to the profane, or the reverse? In fact, it looks like this root *tayaro is primarily linked to the realm of magic and supernatural forces; the profane senses found in Vurës and Mwotlap would result from more recent semantic shift. Indeed, besides the senses cited in (92a), the same root shows various meanings which are all related to supernatural powers. Thus, along with a reflex of ${ }^{\star n} d u l e(59 \mathrm{~b})$, Lo-Toga has a second term for a slightly different sort of haunted stone:

${ }^{\star}$ tayaro $\rightarrow$ 'magic stone in the bush, used as altar for sorcery': LTG toyar

And the neighbouring Hiw has a related verb $t e^{g}$ Lje 'bewitch', used in black magic. This form is the regular reflex of a protoform *tayaro- $a$, i.e. a derived verb bearing the transitivising suffix ${ }^{\star}-a$ (cf. 76):

${ }^{\star}$ tayaro- $a \rightarrow$ 'bewitch, cast a spell on s.o. using sorcery': HIw te ${ }^{g} L j e$

All these elements tend to confirm that the root *tayaro was primarily associated with mythical figures and supernatural forces. Given the variety of its modern reflexes, it is difficult to assign any precise meaning to the etymon. The common denominator between all these senses could perhaps be defined as *tayaro 'a supernatural force embodied in a non-human spirit or a magic stone, and invoked by a sorcerer in bewitching his victims'. In line with Figure 4 above, Figure 5 charts the various senses which northern Vanuatu languages associate with this root.

Finally, Mota (Codrington and Palmer 1896) also has three words reflecting the same root (albeit with an irregular sound correspondence ${ }^{\star} \gamma-{ }^{\star} \eta$ ):

- tanaro 'a morsel of food thrown for a ghost'

- tayaro-na 'a thing belonging to a person which has magic power'

- tanaroa 'stone, carried or hung up in a bag, possessed of magic powers as the abode of a Vui spirit' 


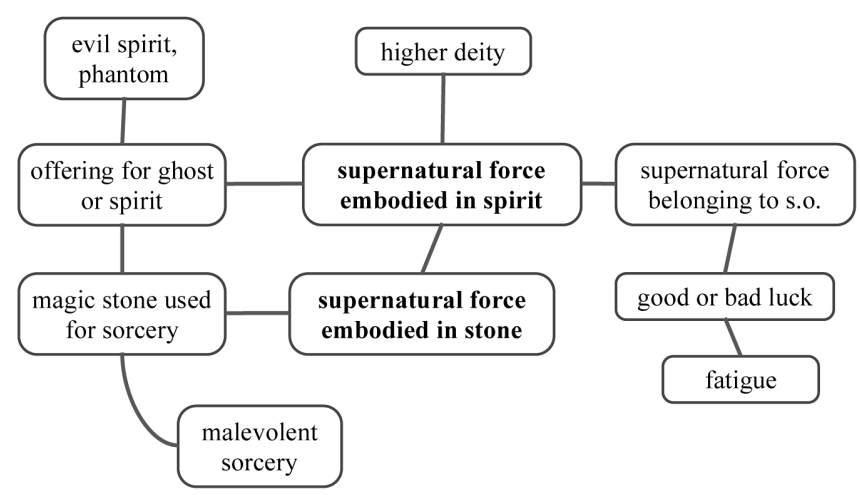

Figure 5: A lexical map for *tayaro 'supernatural force'

The latter form tayaroa is clearly the same word as Dorig/Lakon tayrs 'evil spirit, phantom, ogre' mentioned in §4.4.2. Crucially, it is also homophonous with Tayaroa, the name of the famous Polynesian deity. In fact, we saw that northern Vanuatu languages have a deity *Tayaro (57), the brother of the main deity Qat. Jolly (1996: 241) also mentions tegar as the name of an evil spirit in southern Pentecost, and explicitly points out (p. 257) the similarity with the names of the divinities Tagaro and Tanaroa. In my view, there is no strong reason to hypothesize any Polynesian borrowing here. Given the amount of sound change that has affected its form, and also the deep-reaching connections with other supernatural meanings (Figure 5), it is much more likely that the spiritual force ${ }^{\star}$ Tayaro $\sim{ }^{\star}$ Tayaro was already present in the mythology of the first Oceanic settlers who peopled Vanuatu. If this is true, then ${ }^{\star}$ Tayaro (the form reconstructable at the level of POc) would potentially be the first example of an ancient god whose existence could be reconstructed for the early times of Proto Oceanic unity.

\section{Conclusion}

Due to three millennia of sound change and semantic shift, many words of northern Vanuatu languages have altered their shape or their meaning over time, and have often lost any obvious link with each other. However, should one pay careful attention to sound correspondences so as to avoid false hypotheses, comparison across modern languages makes it possible to retrieve these historical connections between otherwise separate concepts. 
This is how etymological research, applied to the languages of northern Vanuatu, has proven able to unearth the historical links that connect 'mind' and 'inside' (`lolo); 'forget' and 'night' ( ${ }^{\star} b^{w}$ oni); 'soul' and 'shadow' ( $\left.{ }^{\star} a t a\right)$; 'ghost' and 'secret society' ( ${ }^{\star}$ atamate); 'political system' and 'god' ( $\left.{ }^{\star} s u^{m} b^{w} e\right)$; 'deity' and 'root' ( $\left.{ }^{\star} \beta u i\right)$; 'taboo' and 'cemetery' ( $\left.{ }^{\star} t a^{m} b u\right)$; 'Underworld' and 'volcano' (^mbanoi) or 'cave' (`asura); 'world' and 'light' (`marama) ... - to cite but a few. All these connections have now become opaque to the speakers themselves, and would have been difficult to detect solely based on languageinternal analyses: they can only be discovered through a methodical process of cross-linguistic comparison.

Like the spirits who surround the living, the words we speak today are the shadows of bygone lives. The science of etymology provides the linguist with the shamanic power to see the invisible, and bring back to the light of our present world the vanished souls of our ancestors.

\section{References}

Benveniste, Émile. 1969. Le Vocabulaire des Institutions Indo-européennes. 2 volumes. Le Sens Commun. Paris: Minuit.

Biggs, Bruce. 2006. Kimihia te mea ngaro: Seek that which is lost (Memoirs of the Polynesian Society 53). Auckland: Polynesian Society.

Blust, Robert. 1972. Note on PAN *qa(R)(CtT)a 'outsiders, alien people'. Oceanic Linguistics 11. 166-171.

Blust, Robert. 1980. Austronesian Etymologies. Oceanic Linguistics 19 (1/2). 1-189.

Blust, Robert. 1981. Linguistic Evidence for Some Early Austronesian Taboos. American Anthropologist 83 (2). 285-319.

Blust, Robert. 1987. Lexical reconstruction and semantic reconstruction: the case of Austronesian 'house' words. Diachronica 4. 79-106.

Blust, Robert. 2009. The Austronesian languages (Pacific Linguistics 602). Canberra: Australian National University.

Blust, Robert. 2012. Austronesian Comparative Dictionary, web edition. http://www.trussel2.com/ACD (accessed 1 June 2012).

Bolton, Lissant. 2003. Unfolding the moon: Enacting women's kastom in Vanuatu. Honolulu: University of Hawaii Press.

Chantraine, Pierre. 1968-1980. Dictionnaire étymologique de la langue grecque: Histoire des mots. 4 volumes. Paris: Klincksieck.

Charpentier, Jean-Michel \& Alexandre François. forthcoming. Atlas Linguistique de Polynésie Française - Linguistic Atlas of French Polynesia. 2 volumes. Berlin: Mouton de Gruyter.

Clark, Ross. 2009. *Leo Tuai: A comparative lexical study of North and Central Vanuatu languages (Pacific Linguistics 603). Canberra: Australian National University.

Codrington, Robert H. 1885. The Melanesian languages. Oxford: Clarendon Press. 
Codrington, Robert H. 1891. The Melanesians: Studies in their anthropology and folklore. Oxford: Clarendon Press.

Codrington, Robert H. \& John Palmer. 1896. A dictionary of the language of Mota, Sugarloaf Island, Banks Islands. London: Society for Promoting Christian Knowledge.

Crowley, Terry. 2000. The language situation in Vanuatu. Current Issues in Language Planning 1 (1). 47-132.

Dahl, Otto Christian. 1981. Early phonetic and phonemic changes in Austronesian (Institute for Comparative Research in Human Culture series B-63). Oslo: Norwegian University Press.

Dempwolff, Otto. 1969 [1938]. Vergleichende Lautlehre des Austronesischen Wortschatzes: Austronesisches Wörterverzeichnis, 2nd edn. Liechtenstein: Nendeln.

Fox, Charles Elliot. 1962. Kakamora. London: Hodder and Staughton.

Fox, Charles Elliot \& F. H. Drew. 1915. Beliefs and Tales of San Cristoval. The Journal of the Royal Anthropological Institute of Great Britain and Ireland 45. 187-228.

François, Alexandre. 2000a. Vowel shifting and cloning in Motlav: historical explanation vs. formal description. In: M. Klamer (ed.), Proceedings of AFLA7, the 7th Meeting of Austronesian Formal Linguistics Association, 49-68. Amsterdam: Vrije Universiteit.

François, Alexandre. 2000b. Dérivation lexicale et variations d'actance: petits arrangements avec la syntaxe. Bulletin de la Société de Linguistique 95 (1). 15-42.

François, Alexandre. 2002. Araki. A disappearing language of Vanuatu (Pacific Linguistics 522). Canberra: Australian National University.

François, Alexandre. 2005. Unraveling the history of the vowels of seventeen northern Vanuatu languages. Oceanic Linguistics 44 (2). 443-504.

François, Alexandre. 2007. Noun articles in Torres and Banks languages: Conservation and innovation. In: John Lynch, Jeff Siegel and Diana Eades (eds.), Language Description, History and Development: Linguistic Indulgence in Memory of Terry Crowley (Creole Language Library 30), 313-326. Amsterdam \& Philadelphia: John Benjamins.

François, Alexandre. 2008a. Rythmes à danser, poèmes à chanter en Mélanésie: Esthétique, transmission et impact social des arts musicaux au Vanuatu. Final report for the grant “Jeunes Chercheurs" (2004-2007). Paris: LACITO, Centre National de la Recherche Scientifique.

François, Alexandre. 2008b. Semantic maps and the typology of colexification: Intertwining polysemous networks across languages. In: Vanhove, Martine (ed.), From Polysemy to Semantic change: Towards a Typology of Lexical Semantic Associations (Studies in Language Companion Series 106), 163-215. Amsterdam \& Philadelphia: John Benjamins.

François, Alexandre. 2009. The languages of Vanikoro: Three lexicons and one grammar. In: Bethwyn Evans (ed.), Discovering history through language: Papers in honour of Malcolm Ross (Pacific Linguistics 605), 103-126. Canberra: Australian National University.

François, Alexandre. 2010. A comparison of geocentric directionals across Banks and Torres languages. Paper read at the 8th International Congress of Oceanic Linguistics (cool8), University of Auckland (NZ), 4-9 January.

François, Alexandre. 2011a. Where ${ }^{*} \mathrm{R}$ they all? The geography and history of ${ }^{*} \mathrm{R}$ loss in Southern Oceanic languages. Oceanic Linguistics 50 (1). 140-197.

François, Alexandre. 2011b. Social ecology and language history in the northern Vanuatu linkage: A tale of divergence and convergence. Journal of Historical Linguistics 1 (2). 175-246.

François, Alexandre. forthcoming. Voices from the Volcano: Myths, Folktales and Poetry from Gaua, Vanuatu (World Oral Literature Series). Cambridge: Open Book Publishers. 
François, Alexandre. in prep. Systems of geocentric space reference in the languages of northern Vanuatu. In: Alexandre François, Sébastien Lacrampe, Stefan Schnell \& Michael Franjieh (eds.), The Languages of Vanuatu: Unity and Diversity (Studies in the Languages of Island Melanesia). Canberra: Asia Pacific Linguistics Open Access.

François, Alexandre \& Monika Stern. forthcoming. Vanuatu: Celebrations and Mysteries (Inédit). Paris: Maison des Cultures du Monde.

Hess, Sabine. 2009. Person and Place: Ideas, Ideals and the Practice of Sociality on Vanua Lava, Vanuatu. Oxford: Berghahn Books.

Hyslop, Catriona. n.d.a Vera'a-English lexicon. Melbourne: Research Centre for Linguistic Typology. Unpublished lexical files.

Hyslop, Catriona. n.d.b Vurës-English lexicon. Melbourne: Research Centre for Linguistic Typology. Unpublished lexical files.

Ivens, Walter G. 1931. The Place of Vui and Tamate in the Religion of Mota. Royal Anthropological Institute of Great Britain and Ireland 61. 157-166.

Jolly, Margaret. 1996. Devils, Holy Spirits, and the Swollen God: Translation, Conversion and Colonial Power in the Marist Mission, Vanuatu, 1887-1934. In: Peter van der Veer (ed.), Conversion to Modernities: the Globalization of Christianity, 231-262. New York, London: Routledge.

Keesing, Roger. 1984. Rethinking mana. Journal of Anthropological Research 40. 137-156.

Keesing, Roger. 1985. Conventional metaphors and anthropological metaphysics: The problematic of cultural translation. Journal of Anthropological Research 41 (2). 201217.

Koptjevskaja-Tamm, Maria, Martine Vanhove \& Peter Koch. 2007. Typological approaches to lexical semantics. Linguistic Typology 11 (1). 159-186.

Lanouguère-Bruneau. 2002. Le corps de l'igname et le sang de la noix de coco: le système social ancien de Mwotlap (îles Banks, Vanuatu). Paris: École des Hautes Études en Sciences Sociales dissertation.

Lynch, John. 2002. Potent Roots and the Origin of kava. Oceanic Linguistics 41 (2). 493-513.

Lynch, John \& Terry Crowley. 2001. Languages of Vanuatu: A new survey and bibliography

(Pacific Linguistics 517). Canberra: Australian National University.

Marck, Jeff. 1996. The first-order anthropomorphic gods of Polynesia. Journal of the Polynesian Society 105 (2). 217-258.

Mondragón, Carlos. 2004. Of Winds, Worms and Mana: The Traditional Calendar of the Torres Islands, Vanuatu. Oceania 74 (4). 289-308.

Pawley, Andrew. 2003. Locating Proto Oceanic. In: Malcolm Ros; Andrew Pawley \& Meredith Osmond (eds.). 1998. The lexicon of Proto Oceanic: The culture and environment of ancestral Oceanic society. Vol. 1: Material culture (Pacific Linguistics C-152), 17-34. Canberra: Australian National University.

Pawley, Andrew. 2005. The meaning(s) of Proto Oceanic *panua. In: Claudia Gross, Harriet D. Lyons \& Dorothy A. Counts (eds.), A Polymath Anthropologist: Essays In Honour of Ann Chowning. Research in Anthropology and Linguistics, Monograph 6. University of Auckland: Department of Anthropology.

Pawley, Andrew. 2007. The origins of Early Lapita culture: the testimony of historical linguistics. In: Stuart Bedford, Christophe Sand \& Sean P. Connaughton (eds.), Oceanic Explorations: Lapita and Western Pacific Settlement (Terra Australis 26), 17-50. Canberra: ANU E-Press. 
Pawley, Andrew. 2010. Prehistoric Migration and Colonisation Processes in Oceania: A View from Historical Linguistics and Archaeology. In: Jan Lucassen (ed.), Migration history in world history: multidisciplinary approaches (Studies in Global Social History 3), 77-112. Leiden: Brill.

Pawley, Andrew \& Malcolm Ross, eds. 1994. Austronesian Terminologies: Continuity and Change. Pacific Linguistics C-127. Canberra: Australian National University.

Ross, Malcolm. 1988. Proto-Oceanic and the Austronesian languages of Western Melanesia. Pacific Linguistics. Canberra: Australian National University.

Ross, Malcolm, Andrew Pawley \& Meredith Osmond (eds.). 1998. The lexicon of Proto Oceanic: The culture and environment of ancestral Oceanic society. Vol. 1: Material culture (Pacific Linguistics C-152). Canberra: Australian National University.

Ross, Malcolm, Andrew Pawley \& Meredith Osmond (eds.). 2003. The lexicon of Proto Oceanic: The culture and environment of ancestral Oceanic society. Vol. 2: The physical environment (Pacific Linguistics 545). Canberra: Australian National University.

Ross, Malcolm, Andrew Pawley \& Meredith Osmond (eds.). 2008. The lexicon of Proto Oceanic: The culture and environment of ancestral Oceanic society. Vol. 3: Plants (Pacific Linguistics 599). Canberra: Australian National University.

Ross, Malcolm, Andrew Pawley \& Meredith Osmond (eds.). 2011. The lexicon of Proto Oceanic: The culture and environment of ancestral Oceanic society. Vol. 4: Animals (Pacific Linguistics 621). Canberra: Australian National University.

Ross, Malcolm, Andrew Pawley \& Meredith Osmond (eds.). in prep a. The lexicon of Proto Oceanic. People: Body and mind (Pacific Linguistics). Canberra: Australian National University.

Ross, Malcolm, Andrew Pawley \& Meredith Osmond (eds.). in prep $b$. The lexicon of Proto Oceanic. People: Society (Pacific Linguistics). Canberra: Australian National University.

Traugott, Elizabeth C. \& Richard B. Dasher. 2002. Regularity in semantic change (Studies in Linguistics 96). Cambridge: Cambridge University Press.

Tryon, Darrell. 1976. New Hebrides Languages: An internal classification (Pacific Linguistics C-50). Canberra: Australian National University.

Vanhove, Martine (ed.). 2008. From Polysemy to Semantic change: Towards a Typology of Lexical Semantic Associations (Studies in Language Companion Series 106). Amsterdam \& Philadelphia: Benjamins.

Vienne, Bernard. 1972. Les formes du pouvoir et de l'autorité dans les communautés paysannes des îles Banks (Nouvelles-Hébrides). Nouméa, Nouvelle-Calédonie: ORSTOM. Unpublished document.

Vienne, Bernard. 1984. Gens de Motlav. Idéologie et pratique sociale en Mélanésie (Publication de la Société des Océanistes 42). Paris: Société des Océanistes.

Vienne, Bernard. 1996. Masked faces from the country of the Dead. In: Joël Bonnemaison, Kirk Huffman, Christian Kaufmann \& Darrell Tryon (eds.), Arts of Vanuatu, 234-246. Bathurst: Crawford House Press. 